\title{
Characterization of Products from Fast and Isothermal Hydrothermal
}

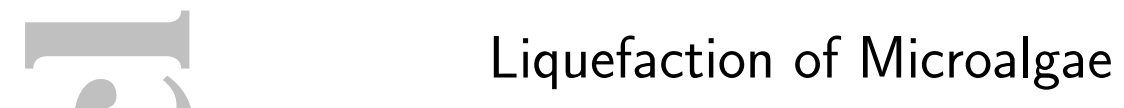

Julia L. Faeth ${ }^{1}$, Jacqueline M. Jarvis ${ }^{2}$, Amy M. McKenna ${ }^{2}$, and Phillip E. Savage ${ }^{1,3}$

${ }^{1}$ Department of Chemical Engineering, University of Michigan, Ann Arbor

${ }^{2}$ National High Magnetic Field Laboratory, Florida State University, Tallahassee

${ }^{3}$ Department of Chemical Engineering, Pennsylvania State University, University Park 1

December 23, 2015

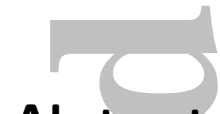

\section{Abstract}

We investigated non-isothermal (fast) and nominally isothermal hydrothermal liquefaction (HTL) of Nannochloropsis sp. microalgae for the production of biocrude. Biocrude yields ranged from $36 \mathrm{wt} \%$ to $45 \mathrm{wt} \%$ (dry weight), with fast HTL with low mass loading giving the highest yield. This condition also gave the biocrude with the lowest heating value, which indicates there are compromises to be made between biocrude quantity and quality. The aqueous phase and biocrude product fractions were characterized using elemental analysis and Fourier Transform Ion Cyclotron Resonance Mass Spectrometry (FT-ICR MS). This detailed level of analysis identified more than 30,000 unique molecular products. The aqueous phase products included compounds with the same molecular formulae as known herbicides, which may inform efforts in genetic engineering of algae and/or bacteria for cultivation on the aqueous phase. This detailed molecular-level characterization provides some clues regarding the types of reactions that may take place during HTL.

Topical Heading Reaction Engineering, Kinetics and Catalysis

Keywords Hydrothermal liquefaction, FT-ICR MS, Microalgae, Biocrude, Aqueous Phase

\section{1}

\footnotetext{
${ }^{1}$ This contribution was identified by Michael Timko (Worcester Polytechnic Institute) as to be a "Best Paper" in the session "Reaction Engineering of Biomass and Hydrocarbons in Supercritical Water" of the 2014 AIChE Annual Meeting in Atlanta, GA.
}

This is the author manuscript accepted for publication and has undergone full peer review but has not been through the copyediting, typesetting, pagination and proofreading process, which may lead to differences between this version and the Version record. Please cite this article as doi:10.1002/ aic.15147. 


\section{Introduction}

Microalgae are attracting attention as a biomass feedstock for renewable fuels due to their high photosynthetic efficiency ${ }^{1}$ and versatility of growth conditions, ${ }^{2}$ among other qualities. Hydrothermal liquefaction (HTL) is a biomass conversion process that takes place in high-temperature, high-pressure water, which obviates the drying required for other biomass conversion processes (e.g. pyrolysis).

Most of the literature on HTL discusses results from experiments lasting for several minutes with a majority of the reaction carried out in an isothermal state. We refer to such conditions as "isothermal" HTL. In contrast, "fast" HTL is defined as an HTL reaction with rapid heating and primarily non-isothermal operation. The reaction lasts for, at most, a few minutes. Shorter reaction times require smaller reactors, which could reduce the capital cost of industrial-scale HTL processes. Since the initial report on fast HTL by Faeth et al., ${ }^{3}$ it has been applied to macroalgae ${ }^{4}$ and various microbes. ${ }^{5}$

The methods used to characterize products from HTL include elemental analysis, simulated distillation, total organic and inorganic carbon analysis, and ammonia analysis, none of which provide information about the molecular composition of the HTL products. Some studies investigating isothermal HTL reported molecular characterization of product fractions using gas chromatography with a mass spectrometric detector (GC-MS), but this method provides information only about the more volatile compounds that can elute from the GC. Fourier Transform lon Cyclotron Resonance Mass Spectrometry (FT-ICR MS), on the other hand, provides a much more complete molecular characterization of the products. FT-ICR MS has been used to characterize petroleum crude oils, ${ }^{6-12}$ some products of biomass conversion processes, ${ }^{13-24}$ and the processing water from oil sands ${ }^{25}$ in molecular detail.

To the best of our knowledge, analysis of the biocrude and/or aqueous phase products from HTL of microalgae using FT-ICR MS has been reported previously only by Sudasinghe et al. ${ }^{14,15}$ and Sanguineti et al., ${ }^{16}$ though Levine et al. used FT-ICR MS to characterize the aqueous phase co-product from hydrothermal carbonization of microalgae. $^{13}$ This present study is the first to apply FT-ICR MS characterization to the products of fast HTL and it is also the first to provide a detailed characterization and comparison of products from fast and isothermal HTL reaction conditions. Herein we characterize the biocrude and aqueous phase product fractions from both isothermal and fast HTL using FT-ICR MS and elemental analysis. These data provide new information about the composition of these complex mixtures and illustrate the potential advantages and disadvantages of each biomass conversion process for the production of biocrude from microalgae. 


\section{Materials and Methods}

\section{Materials}

Nannochloropsis sp., was purchased as a paste from Reed Mariculture Inc. The algae were from the same lot as reported in previous work, ${ }^{3}$ and therefore contain $32.5 \mathrm{wt} \%$ solids in the paste and $6.25 \pm 0.23 \mathrm{wt} \%$ ash in the dry solids. All chemicals were purchased from the same sources and are identical to those used in previous work. 3,26 Reactors were constructed from $1 / 2$ in. Swagelok ${ }^{\circledR} 316$ stainless steel port connectors. A $1 / 2$ in. cap sealed one end of the port connector, and a $1 / 2$ to $1 / 8 \mathrm{in}$. reducing union sealed the other side. The $1 / 8$ in. end of the reducing union was connected to $8.5 \mathrm{in.}$ of $1 / 8 \mathrm{in.}$ stainless steel tubing and a High Pressure Equipment Co. high pressure valve. The internal reactor volume, including the gas valve assembly, was $4.6 \mathrm{~mL}$. After assembly, reactors were conditioned before use. To do this, reactors were loaded with deionized water such that $95 \%$ of the reactor volume would be occupied by liquid water at reaction conditions, sealed, and submerged in a preheated Techne IFB-51 fluidized sandbath with a Eurotherm 3216 PID controller at $350{ }^{\circ} \mathrm{C}$ for one hour. Then the reactors were cooled and cleaned. This procedure removed any residual material inside the reactors prior to use in HTL reactions.

\section{Experimental Methods}

Either 0.25 or $1.54 \mathrm{~g}$ of algae slurry (32.5 wt \% solids) were loaded into a pre-conditioned reactor. An additional 0.29 or $1.74 \mathrm{~mL}$ of deionized water was added to dilute the slurry to $15 \mathrm{wt} \%$ solids. Reactor loadings are reported in Table S1 in the Supplementary Information (SI). Both loadings were used in fast HTL experiments and only the higher loading was used in isothermal HTL. The low loading resulted in $10 \%$ of the reactor volume being occupied by water at ambient conditions and the high loading corresponded to $60 \%$. The headspace contained ambient air, which was sealed inside the loaded reactor. Loaded, sealed reactors were submerged in a preheated fluidized sandbath, set at $300{ }^{\circ} \mathrm{C}$ for isothermal $\mathrm{HTL}$ and $600{ }^{\circ} \mathrm{C}$ for fast $\mathrm{HTL}$. The reaction time was defined to start as soon as the reactor was submerged in the sandbath. Reaction times were 20 min for isothermal HTL and 1 min for fast HTL.

After the specified reaction time, reactors were immediately quenched in cold water and allowed to equilibrate at room temperature for $15 \mathrm{~min}$. Table 1 shows the reaction conditions explored in this work. Temperatures were recorded using two thermocouple-equipped dummy reactors, constructed as described previously. ${ }^{3}$ These dummy reactors provided an estimate of the temperatures experienced by the HTL reactors. The average of the data from these dummy reactors provided the characteristic temperature profile for that respective reaction condition. The pressure and headspace volume fractions in Table 1 were calculated using steam tables and the 
experimental temperature data. The reaction ordinate $\left(R_{0}\right)$, a single parameter that describes the reaction severity, was calculated for the entire reaction time (not including quench), as described by Faeth et al. ${ }^{3}$

Figure 1 displays the reactor temperature profiles. The fast $\mathrm{HTL}$ reactors reached $186^{\circ} \mathrm{C}$, and the isothermal $\mathrm{HTL}$ reactors reached $279^{\circ} \mathrm{C}$. This ultimate reactor temperature for the isothermal run differs from the set point temperature, which illustrates the importance of using a direct measurement of the reactor temperature. The careful reader will note that the temperature profiles in Figure 1 differ from those in our earlier work. ${ }^{3}$ This difference arises from the use of larger reactors in the present study.

\section{Product Recovery and Elemental Analysis}

Gaseous products were analyzed using an Agilent Technologies model 6890 gas chromatograph (GC) equipped with a thermal conductivity detector (TCD), as described by Brown et al. ${ }^{27}$ The nitrogen initially present in the headspace of the sealed reactor (calculated using the ideal gas law) served as an internal standard to determine the yields of hydrogen, carbon monoxide, carbon dioxide, methane, ethane, and ethene. Once gas analysis was complete, the valve assembly was removed and the contents of the reactor were poured into a glass conical centrifuge tube. The reactor was rinsed with $9 \mathrm{~mL}$ of dichloromethane, and the rinsings were collected and added to the same centrifuge tube. The procedure for separating the aqueous phase, organic phase, and residual solids was described previously and involves centrifugation and manual transfer of phases using a glass pipet. ${ }^{26}$

The product fractions were dried under nitrogen using a Labconco ${ }^{\circledR}$ RapidVap ${ }^{\circledR}$ Vertex ${ }^{\top M}$ Dry Evaporator. The solvent-free dichloromethane-soluble organic phase is identified as the biocrude. The masses of each dried sample were recorded and divided by the mass of dry algae initially loaded in the reactor to calculate the gravimetric yields of each product fraction on a dry basis. All reactions were carried out in duplicate. One of the dried aqueous phase samples and one of the biocrude samples from each set of duplicates were sent to Atlantic Microlabs, Inc. for analysis of $\mathrm{C}, \mathrm{H}, \mathrm{N}$, and $\mathrm{S}$. O was calculated by difference. The remaining dried aqueous phase and biocrude samples were sent to the National High Magnetic Field Laboratory for analysis by FT-ICR MS, as described in the next subsection.

\section{FT-ICR MS Analysis}

Dried aqueous phase samples were prepared for analysis by positive and negative mode electrospray ionization (ESI) at a concentration of $500 \mu \mathrm{g} / \mathrm{mL} 50: 50(\mathrm{v} / \mathrm{v})$ water:methanol. Dried biocrude samples were prepared for analysis at a concentration of $250 \mu \mathrm{g} / \mathrm{mL} 50: 50(\mathrm{v} / \mathrm{v})$ dichloromethane:methanol. For positive mode ESI, $1 \%$ $(\mathrm{v} / \mathrm{v})$ formic acid was added to aid in protonation. For negative mode ESI, $1 \%(\mathrm{v} / \mathrm{v})$ ammonium hydroxide solution (28\% in water) was added to aid in deprotonation. 
Samples were analyzed with a custom-built 9.4 T Fourier transform ion cyclotron resonance mass spectrometer. ${ }^{28}$ Data collection was facilitated by a modular ICR data acquisition system (PREDATOR). ${ }^{29}$ Multiple (75-150) individual time-domain transients were co-added, half-Hanning-apodized, zero-filled, and fast Fourier transformed prior to frequency conversion to mass-to-charge ratio to obtain the final mass spectrum in absorption mode. ${ }^{30,31}$ ICR frequencies were converted to ion masses based on the quadrupolar trapping potential approximation. ${ }^{6}$

External calibration of the instrument is performed monthly by use of ESI tuning mix (Agilent, Santa Clara, CA) to correct for temporal drift of the magnetic field. Internal calibration of the spectrum was possible with the use of homologous series which repeat by $14.01565 \mathrm{Da}$ (or $\mathrm{CH}_{2}$ units). All of the negative mode spectra (for both aqueous phase and biocrude samples) and the positive mode spectra for aqueous phase samples were manually calibrated on multiple homologous series because no one series spanned the entire $\mathrm{m} / \mathrm{z}$ range. However, the positive mode spectra for biocrude samples included a homologous series that did span the entire $\mathrm{m} / \mathrm{z}$ range so these spectra were calibrated by "walking calibration". 32,33 To capture the most abundant compounds in the samples from HTL of Nannochloropsis sp., FT-ICR MS excite and detect parameters were adjusted such that ions below $200 \mathrm{~m} / \mathrm{z}$ were not collected.

IUPAC mass can be converted to Kendrick mass (Kendrick mass = IUPAC mass $\times(14 / 14.01565)$ ) to sort compounds that differ in mass by $14.01565 \mathrm{Da}$ (mass of $\mathrm{CH}_{2}$ ). ${ }^{34}$ Mass spectral peaks with signal magnitude greater than six times the baseline root-mean-square (RMS) noise level were assigned elemental compositions with custom-built software (MIDAS). Peak assignments and data visualization were performed with PetroOrg software. ${ }^{35}$ For all mass spectra, the achieved spectral resolving power approached the theoretical limit ${ }^{6}$ over the entire mass range: for example, average resolving power, $\mathrm{m} / \Delta \mathrm{m}_{50 \%}$, in which $\Delta \mathrm{m}_{50 \%}$ is mass spectral peak full width at half-maximum peak height, was $\sim 1,000,000-1,300,00$ at $\mathrm{m} / \mathrm{z} 500$.

\section{Results and Discussion}

The product yields from each HTL reaction condition are reported in this section, along with the molecular and/or elemental characterization of the gaseous, aqueous phase, and biocrude products. The results from FT-ICR MS analysis are displayed in a variety of different formats, including broadband spectra, van Krevelen Plots, heteroatom density plots, and isoabundance contour plots (plots of the last type were generated using PetroOrg software ${ }^{35}$ ). Figure 2 depicts a simplified scheme of some reactions likely to take place during $H T L$, based on reports in the literature and the results of the present work. Discussion of the reactions depicted in Figure 2 is included in the following sections. 


\section{Product Yields, Recovery, and Elemental Analysis}

Table 2 provides the average product yields for each reaction condition. The gas, aqueous phase, biocrude, and solid product yields are largely comparable to those observed in previous studies of the same algae processed with similar reaction severity. ${ }^{3,26}$ An exception is the biocrude yield from fast HTL with the high loading, which was slightly lower than expected based on the variation of biocrude yield with reaction ordinate $\left(R_{0}\right)$ reported by Faeth et al. ${ }^{3}$ This departure from the trend reported previously may be the result of increased mass loading in the present work. Fast HTL with low loading produced the most biocrude, and fast HTL with high loading produced approximately the same amount of biocrude as did isothermal HTL. Solid yields are slightly lower after isothermal HTL than from either fast HTL reaction, likely due to the increase in reaction severity characteristic of isothermal HTL. Aqueous phase yields are fairly consistent after all three HTL reaction conditions.

Higher gas yields were obtained after fast HTL at the low loading. These observations indicate that mass loading has a significant effect on product formation. To the best of our knowledge, this is the first report indicating that mass loading (not just the concentration of algae in the reaction mixture) impacts product formation during HTL in batch systems. We propose that mass loading effects are observed because of a change in the "effective concentration" of the compounds which constitute the biomass in the liquid water phase. With the lower water loading and larger headspace volume, proportionately more water would partition into the vapor phase and the algal biomass would be more concentrated in the liquid phase.

\section{Gas Analysis}

Table 3 highlights the molar yields of gaseous products per gram of dry algae loaded into the reactor. Only gases containing $\mathrm{C}$ and/or $\mathrm{H}$ are included in Table 3, as these are produced by the reaction. For all reaction conditions, $\mathrm{CO}_{2}$ is the dominant product with yields $\geq 0.3 \mathrm{mmol} / \mathrm{g}$ dry algae. $\mathrm{CO}$ is the second most abundant product, contributing up to $0.12 \mathrm{mmol} / \mathrm{g}$ algae. Comparing the gases from the two fast HTL reaction conditions with those from isothermal $\mathrm{HTL}$ reveals that isothermal $\mathrm{HTL}$ results in more completely oxidized gases and no $\mathrm{C}_{2}$ gases. Oxidation of propane and other short-chain hydrocarbons in subcritical water has been observed previously, ${ }^{36}$ which provides a possible explanation for the gas products from isothermal HTL.

Similar yields of $\mathrm{CO}_{2}$ are observed after $\mathrm{HTL}$ at both of the high loading reaction conditions, which may indicate that the mass loading in the reactor has more influence on $\mathrm{CO}_{2}$ production than does the reaction severity. This observation further supports the idea that mass loading affects product formation during HTL, possibly by manipulating the effective concentration of biomass in liquid water, as mentioned previously.

6

AlChE Journal 


\section{Elemental Composition of Aqueous Phase and Biocrude}

This section provides the elemental composition of the dried aqueous phase and biocrude product fractions. Higher heating values were calculated from the elemental compositions using the Boie formula. ${ }^{37}$ We also calculated the recovery of $\mathrm{C}, \mathrm{N}$, and $\mathrm{S}$ in the dried aqueous phase and biocrude samples, according to Equation 1 and displayed in Figures $\mathrm{S} 1$ and $\mathrm{S} 2$ in the $\mathrm{SI}$.

$$
\text { Recovery of Element } X(\%)=\frac{W_{t} \% X \text { in Product Fraction } \times \text { Mass of Product Fraction }}{\mathrm{Wt}_{\mathrm{t}} \mathrm{X} \text { in Dry Algae } \times \text { Mass of Dry Algae Loaded }}
$$

Table 4 displays the elemental compositions for the dried aqueous phase samples from all three experimental conditions. All three aqueous phase samples have similar $\mathrm{H}$ and $\mathrm{S}$ content, but fast $\mathrm{HTL}$ with the low loading appears to produce an aqueous phase co-product with less $\mathrm{C}$ and $\mathrm{N}$ than the other two conditions.

The lower $\mathrm{C}$ and $\mathrm{N}$ content in the aqueous phase from fast $\mathrm{HTL}$ with low loading may be due to the presence of a different reaction environment: an increase in the effective concentration of algal compounds in the liquid water phase. This increase in effective concentration during HTL seems to facilitate reactions that favor partitioning of $\mathrm{C}$ - and $\mathrm{N}$-containing compounds into the biocrude rather than into the aqueous phase, which is consistent with both the increase in biocrude yield and decrease in $\mathrm{C}$ and $\mathrm{N}$ content of the aqueous phase from fast $\mathrm{HTL}$ at the low loading HTL condition. Such reactions may include the formation of amides (from the combination of fatty acids and amino acids and/or ammonia) and Maillard reaction products (from the combination of amino acids and sugars), both depicted in Figure 2.

In contrast, fast HTL with the high loading produced the aqueous phase product with the highest $\mathrm{C}$ and $\mathrm{N}$ content. The amount of $\mathrm{C}$ and $\mathrm{N}$ in the aqueous phase at this condition accounts for $31.5 \%$ of the $\mathrm{C}$ and 54.6 $\%$ of the $\mathrm{N}$ in the algal biomass loaded into the reactor (see Fig. S1). Hydrolysis of proteins into water-soluble amino acids and/or amino acid chains (peptides and polypeptides), as illustrated in Figure 2, is known to occur very quickly in subcritical water, ${ }^{38}$ and likely took place during all reactions in the present work. However, fast HTL with the low loading and isothermal HTL may provide enhanced opportunities for reactions of these protein components with other compounds to produce the aforementioned amides and Maillard reaction products, via an increase in the effective concentration and an extended reaction time, respectively. Therefore, the high $\mathrm{C}$ and $\mathrm{N}$ content in the aqueous phase from fast HTL with the high loading may be due to rapid protein hydrolysis followed by a rapid quench before reactions of water-soluble protein components can occur to a significant extent.

Fast HTL with the high loading led to the highest recovery of $\mathrm{N}$ in the aqueous phase, which is desirable as it reduces heteroatoms in the biocrude and facilitates nutrient recycling to algae cultivation ponds or bioreactors. This condition also led to a higher $\mathrm{C}$ recovery in the aqueous phase, which is undesired as it partially deprives the biocrude fraction of $C$. These results clearly indicate that trade-offs exist between minimizing $C$ and maximizing 
$\mathrm{N}$ in the aqueous phase.

Table 5 shows the elemental composition and HHV of the biocrude samples. The biocrude from fast HTL at the high loading contains the least $\mathrm{N}$ and $\mathrm{O}$. The low $\mathrm{N}$ content, which represents just $25.7 \%$ of the $\mathrm{N}$ in the algal biomass, is consistent with fast HTL with the high loading favoring rapid solubilization of protein-derived (and likely $\mathrm{N}$-containing) products that partition into the aqueous phase. Further, biocrude from fast HTL with the low loading contained the most $\mathrm{N}(44.5 \%$ of the $\mathrm{N}$ in the algal biomass feedstock) and lowest HHV of all three biocrude samples. As energy density and $\mathrm{N}$ content can be proxies for biocrude quality, this condition produced the lowest quality biocrude. Recall, however, that this reaction condition also resulted in the highest biocrude yield.

Fast HTL with the low loading leads to the highest $\mathrm{C}$ recovery (61.0\% of the $\mathrm{C}$ in the algae) in the biocrude of the reaction conditions examined, but it also leads to the highest N (44.5\%) and S (48.6\%) recoveries (see Fig. S2). Heteroatoms decrease the energy content of a fuel and produce harmful substances upon combustion. In exchange for lower $\mathrm{N}$ and $\mathrm{S}$ recoveries in the biocrude, fast HTL with the high loading and isothermal HTL also led to a lower $\mathrm{C}$ recovery. Again, we observe competing effects of the HTL conditions on the $\mathrm{C}$ and heteroatom recoveries in the biocrude, and between biocrude yield and quality. These trade-offs point to the need to optimize $\mathrm{HTL}$ reaction conditions to obtain high quality products at acceptable yields.

\section{FT-ICR MS Analysis}

The preceding section identified trade-offs between the recovery of $C$ and the recovery of heteroatoms to both the aqueous phase and biocrude products, and between yield and quality of the biocrude. This section reports on the use of high-resolution FT-ICR MS analysis to better understand how the different reaction conditions affect HTL product yields and compositions.

\section{Distribution and Ionization of Product Molecules}

The high resolution of FT-ICR MS permitted assignment of molecular formulae to up to $95 \%$ of the peaks in the broadband MS spectra (see Table S2 in the SI for further details on peak assignment). Figure 3 depicts the positive ESI FT-ICR MS broadband spectra for the aqueous phase samples. These spectra illustrate relative abundances of the various compounds present over the range of molecular weights analyzed. Large peaks appear in the 300 - 400 mass-to-charge ratio $(\mathrm{m} / \mathrm{z})$ region for all three HTL reactions. The most abundant compounds in the aqueous phase from isothermal HTL (spectrum C) are concentrated in a lower range of $\mathrm{m} / \mathrm{z}$ than are the most abundant compounds in the aqueous phase samples from fast HTL. Fast HTL with the high loading (spectrum B) produced more water-soluble compounds with high $\mathrm{m} / \mathrm{z}$ than did the other reaction conditions. Additionally, the 
highest number of assignable peaks was in the spectrum for the aqueous phase from fast HTL with low loading (spectrum A). Figures S3 - S5 in the SI provide additional broadband spectra for the aqueous phase (negative ESI) and biocrude (positive and negative ESI).

Using both positive and negative ESI FT-ICR MS, we identified more than 13,000 unique molecular formulae in each of the aqueous phase samples and over 25,000 unique molecular formulae in each of the biocrude samples. These counts exceed those reported by Sudasinghe et al. by at least a factor of three. ${ }^{14}$ The relative number of molecular formulae identified by positive ESI and negative ESI are depicted using Venn diagrams in Figure $4 .{ }^{39}$ The size of the left circle of each diagram corresponds to the number of unique molecular formulae identified using positive ESI alone. The overlapping (middle) and right sections of each diagram correspond to the number of unique molecular formulae identified using both ESI methods and negative ESI alone, respectively. The labels of each of these portions indicate the actual number of peaks identified by positive, negative, or both methods of ionization. Please note that the circles in Figure 4 scale within a given sample type (aqueous phase or biocrude), but not across different types of samples.

Figure 4a shows that more unique compounds in the aqueous phase samples were identified using negative ESI than with positive ESI for all HTL processing conditions in this work. Compounds readily detected by negative ESI include those with acidic functional groups (like carboxylic acids) and those containing oxygen atoms. ${ }^{40}$ Compounds readily detected by positive ESI include those with basic functional groups (like pyridine and related compounds) and those containing nitrogen atoms. ${ }^{40}$ More compounds in the aqueous phase being identified by negative ESI (rather than positive ESI) likely indicates that the aqueous phase samples examined in this study contain more compounds with acidic functional groups (or with more $\mathrm{O}$ atoms) than with basic functional groups.

It is clear from Figure $4 \mathrm{~b}$ that a large majority of the unique compounds identified in the biocrude samples produced under all three reaction conditions were ionized using positive ESI. Based on the likely composition of the compounds identified using each ionization method, the biocrude samples are likely to contain a larger fraction of compounds with basic, rather than acidic, functional groups than do the aqueous phase samples. This result is consistent with the observations of Sudasinghe et al. ${ }^{14}$

Of the acidic compounds identified in the biocrude, the most abundant are C16 - C20 compounds. Figure 5 depicts the relative abundance fraction of compounds of each carbon number in the biocrude, analyzed using negative ESI. The three carbon numbers with the most abundant compounds are 20,16 , and 18 , in decreasing order. These carbon numbers also correspond to the most abundant fatty acids in Nannochloropsis sp. ${ }^{41}$ In fact, we identified a compound with molecular formula $\mathrm{C}_{20} \mathrm{H}_{30} \mathrm{O}_{2}$ and a double bond equivalent (DBE) of 5 in all three biocrude samples analyzed using negative ESI. The DBE represents the degree of unsaturation of a molecule, with the number indicating the sum of rings and double bonds. For example, cyclohexane has a DBE of 1 to represent 1 ring, while benzene has a DBE of 4, representing 1 ring and 3 double bonds. This molecular identification 
matches that of eicosapentaenoic acid (EPA, C20:5 $\omega-3$ ), the most abundant fatty acid detected in a different study with Nannochloropsis sp. biomass. ${ }^{41}$ We also note that some compounds in the C16 - C20 range contain multiple $\mathrm{N}$ and $\mathrm{O}$ atoms and have molecular formulae consistent with chains of amino acids.

Compounds with $16-20 \mathrm{C}$ atoms are also among the most abundant in the aqueous phase samples analyzed using negative ESI, as Figure 6 depicts. These compounds may include free fatty acids, but many of them contain several heteroatoms. In fact, the aqueous phase from fast HTL with high loading contains C20 compounds with up to $8 \mathrm{~N}$ atoms and $6 \mathrm{O}$ atoms. Such compounds are consistent with chains of 4 amino acids, indicating that many of the water-soluble compounds with carbon numbers of $16-20$ may be derived from proteins. Carbon number distribution plots for the aqueous phase and biocrude analyzed using positive ESI are included in the SI (Figures S6 and S7).

\section{Heteroatoms}

This section provides information about the heteroatom content and distribution in the products from the three HTL conditions examined. We first explore O-containing compounds, followed by compounds containing both $\mathrm{N}$ and $\mathrm{O}, \mathrm{N}$-containing compounds, Na-containing compounds, and S-containing compounds. Since more compounds in the aqueous phase samples were identified using negative ESI, the remainder of the aqueous phase analysis in this work is restricted to negative ESI unless indicated otherwise. Likewise, more compounds in the biocrude samples were identified using positive ESI, so the remainder of the analysis of biocrude samples in this article is restricted to positive ESI unless otherwise indicated.

Oxygen-Containing Compounds

One way to visualize FT-ICR MS results for O-containing compounds is via the van Krevelen plot, which displays the $\mathrm{H} / \mathrm{C}$ ratio of each compound with respect to its $\mathrm{O} / \mathrm{C}$ ratio. ${ }^{42}$ Different types of compounds appear in different regions of the plot, which can help characterize the composition of the samples. Biocrude and aqueous phase samples produced via HTL of microalgae may contain lipids, proteins, phenolic polymers, unsaturated hydrocarbons, aromatics, and products derived therefrom. Lipids generally have $\mathrm{H} / \mathrm{C}$ from $1.7-2.2$ and $\mathrm{O} / \mathrm{C}$ from 0.0 - 0.2. Proteins lie between $1.5-2.2 \mathrm{H} / \mathrm{C}$ and $0.2-0.6 \mathrm{O} / \mathrm{C}$, phenolic polymers between $0.6-1.7 \mathrm{H} / \mathrm{C}$ and $0.1-0.6 \mathrm{O} / \mathrm{C}$, unsaturated hydrocarbons between $0.7-1.5 \mathrm{H} / \mathrm{C}$ and $0.0-0.1 \mathrm{O} / \mathrm{C}$, and aromatics between $0.3-0.7 \mathrm{H} / \mathrm{C}$ and $0.0-1.0 \mathrm{O} / \mathrm{C}^{13}$ Further, different collections of data points on a van Krevelen plot can identify chemical reactions that relate the compounds in the group. For example, a grouping of points on a line with a slope of 2 may indicate compounds that are related to each other by hydration or condensation, and a horizontal line indicates compounds related by oxidation or reduction. ${ }^{42,43}$ 
Figure 7 depicts a van Krevelen plot of the compounds identified via negative ESI of the aqueous phase samples from HTL. All three samples contain many compounds that appear in the regions expected for phenolic polymers and proteins. Some compounds also fall into the lipid region on these plots, which may indicate some solubility in water for energy-dense compounds like lipids. Based on the arrangement of points on these plots, there appear to be compounds related by oxidation/reduction, hydrogenation/dehydrogenation, methylation/demethylation/alkyl chain elongation, hydration/dehydration, and carboxylation/decarboxylation reactions (as described above, and in greater detail in references ${ }^{42}$ and $^{43}$ ).

Figure 8 depicts van Krevelen plots for biocrude samples analyzed by positive ESI FT-ICR MS. All three biocrude samples contain many compounds within the regions representing phenolic polymers, lipids, and unsaturated hydrocarbons. Figure 8 shows fewer compounds with $\mathrm{O} / \mathrm{C}$ ratios $>0.3$, than were present in the aqueous phase samples. Positive ESI identified the most compounds with $\mathrm{O} / \mathrm{C}$ ratios $>0.3$ in the biocrude from isothermal HTL (317), though all three HTL processing conditions yield similar numbers of compounds with high O/C (241 and 273 from fast, low loading and fast, high loading HTL, respectively). However, isothermal HTL produced far fewer acidic (identified using negative ESI) compounds with $\mathrm{O} / \mathrm{C}$ ratios $>0.3$ than did fast $\mathrm{HTL}$ (51 from isothermal HTL compared to 329 and 139 from fast, low loading and fast, high loading HTL, respectively). The additional reaction time (and greater reaction severity) may provide additional time for reactions between compounds, possibly converting acidic compounds to more basic ones through the addition of nitrogen. The Maillard Reaction and interactions between protein components and lipid products (depicted in Figure 2) could both contribute to the addition of $\mathrm{N}$.

$\mathrm{N}_{x} \mathrm{O}_{y}$ Compounds

Since $\mathrm{N}$ and $\mathrm{O}$ are the most abundant heteroatoms, we examine how these two elements are combined in the various compounds identified. Figures 9 and 10 depict the relative abundance (color scale) of distinct compounds in different heteroatom classes ( $\mathrm{O}$ on the horizontal axis and $\mathrm{N}$ on the vertical axis) for the aqueous phase and biocrude samples, respectively. In FT-ICR MS, relative abundance does not correspond directly to a mass or molar basis, but is a function of how many ions move past the detector, the distance between the ions and the detector, and how long the ions can be detected. As a result, the relative abundance resulting from FT-ICR MS analysis is a qualitative representation of the sample composition.

Figure 9 shows that fast HTL with high loading produced aqueous phase compounds that contained the highest number of $\mathrm{N}$ and $\mathrm{O}$ atoms $\left(\mathrm{N}_{10} \mathrm{O}_{12}\right)$, compared to the other two reaction conditions (for which $\mathrm{N}_{8} \mathrm{O}_{9}$ is the highest heteroatom class observed). Though the mass loadings are the same, the product distributions in Figure 9 for fast HTL with high loading and isothermal HTL are quite different. The most abundant compounds 
in the aqueous phase from isothermal $\mathrm{HTL}$ belong to the $\mathrm{N}_{3} \mathrm{O}_{5}$ class and classes within one or two $\mathrm{N}$ and/or $\mathrm{O}$ atoms. It seems that the compounds that formed initially during fast HTL underwent additional hydrolysis or decomposition to form compounds with fewer $\mathrm{N}$ and $\mathrm{O}$ atoms. Figure $\mathrm{S} 8$ in the $\mathrm{SI}$ depicts similar trends.

Figure 10 depicts heteroatom density graphs for the biocrude samples analyzed using positive ESI. Several compounds with no $\mathrm{N}$ atoms are present in the biocrudes from fast HTL, but all compounds in the biocrude from isothermal HTL contain at least $1 \mathrm{~N}$ atom (after analysis by positive ESI). Sudasinghe et al. observed several compounds with no $\mathrm{N}$ atoms and $4 \mathrm{O}$ atoms in their biocrude, which they believed to be polymerized fatty acids. ${ }^{14}$ It is possible that the compounds with no $\mathrm{N}$ and $3-7 \mathrm{O}$ atoms identified in the biocrude samples produced via fast HTL are also polymerized fatty acids with varying levels of oxygenation. Since none of these compounds are present in the biocrude produced via isothermal HTL, it is likely that the extended reaction time facilitated reactions of fatty acids and/or polymerized fatty acids with amino acids, ammonia, or other $\mathrm{N}$-containing compounds, as depicted in Figure 2.

This scenario is consistent with the observation from the section discussing O-containing compounds that the high $\mathrm{O} / \mathrm{C}$ compounds in the biocrude from isothermal HTL are primarily ionized by positive ESI (which ionizes Ncontaining and basic compounds). Sudasinghe et al. observed an increase in the relative abundance of compounds containing both $\mathrm{N}$ and $\mathrm{O}$ with increasing temperature, ${ }^{15}$ which may also contribute to the paucity of compounds deemed likely to be polymerized fatty acids in the biocrude from isothermal HTL. As indicated in Table 1, the maximum reaction temperatures increased from $186{ }^{\circ} \mathrm{C}$ for the fast $\mathrm{HTL}$ reactions to $279{ }^{\circ} \mathrm{C}$ for the isothermal HTL reaction.

The negative ESI analysis of the biocrude samples from all three reaction conditions (depicted in Fig. S9 in the SI) contained several compounds with $2 \mathrm{O}$ atoms and no N atoms. In fact, such compounds contribute 33 $44 \%$ of the total relative abundance. Figure S9 in the SI highlights the vast abundance of compounds with 20 atoms in the biocrude analyzed by negative ESI. Many of these compounds are likely fatty acids, which indicates that reactions of $\mathrm{N}$-containing compounds with fatty acids and/or polymerized fatty acids do not consume all of these compounds, even after isothermal HTL.

Isoabundance contour plots provide yet another way to depict characteristics of the numerous compounds containing both $\mathrm{N}$ and $\mathrm{O}$ atoms. As a representative example, Figure 11 displays isoabundance contour plots for the heteroatom class $\mathrm{N}_{3} \mathrm{O}_{4}$. The number of $\mathrm{C}$ atoms present in a particular compound is on the horizontal axis, and the DBE is on the vertical axis. The color scale indicates the relative abundance of the compounds. Isoabundance contour plots of heteroatom class density can build a comprehensive "fingerprint" of the samples analyzed by FT-ICR MS. This fingerprint provides a very detailed accounting of the size of the compounds, degree of unsaturation, and the distribution of different types of compounds, all of which can be very useful when considering these samples for upgrading. 
The plots in the top row (panels $\mathrm{A}, \mathrm{B}$, and $\mathrm{C}$ ) of Figure 11 depict results for the aqueous phase samples, and the plots in the bottom row (panels D, E, and F) show results for the biocrude, both analyzed using positive ESI. The biocrudes contain a more diverse distribution of compounds in this particular heteroatom class than do the aqueous phase samples, perhaps because of the larger number of compounds present in the biocrudes relative to the aqueous phase. The plots of both the aqueous phase and the biocrude from fast HTL at the high loading have two small regions of high relative abundance instead of a single "hot spot" as observed in the other plots. The results for the samples produced using isothermal HTL and fast HTL with low loading are quite similar. Recall that the heteroatom density plots for these samples were also similar.

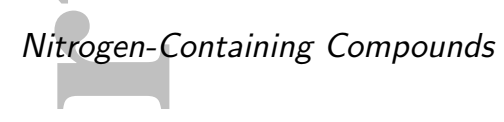

$\mathrm{N}$ is abundant in protein-rich biomass, such as many algal species. It is important to understand how $\mathrm{N}$ is included in the various compounds in the aqueous phase and biocrude from HTL to facilitate upgrading of these compounds to usable fuels and nutrient sources. Figure 12 depicts the $\mathrm{N} / \mathrm{C}$ ratios plotted with the molecular weight in units of atomic mass unit (AMU) for the aqueous phase samples. This plot illustrates how $\mathrm{N}$ is incorporated into molecules of different sizes in the aqueous phase. Most compounds in all three samples have molecular weights between 200-800 AMU and the compounds with the highest N/C ratios are within the $250-500$ AMU range. The aqueous phase from fast HTL with the high loading is the only aqueous phase sample analyzed by negative ESI that contains compounds with molecular weights $>800$ AMU. These compounds primarily have N/C ratios of 0.1 -0.3. Select molecular formulae of compounds with molecular weights $>800 \mathrm{AMU}$ and their respective DBE values are consistent with those of various polypeptide chains. This tentative identification supports the idea that fast HTL with high loading facilitates solubilization of peptides and/or polypeptides, and that the reaction is quenched prior to significant decomposition of these products.

Most $\mathrm{N}$-containing compounds in the biocrude samples also have molecular weights $<800 \mathrm{AMU}$ (see Fig. $\mathrm{S} 10$ in the SI). Biocrude samples generated under high loading conditions from both fast and isothermal HTL include the most N-containing compounds at molecular weights above 800 AMU (3303, followed by 2013 and 1139 from fast, high loading and fast, low loading HTL, respectively). However, elemental analysis (Table 5) revealed that the biocrude from fast HTL with the high loading contains the least $\mathrm{N}$ overall, followed closely by the biocrude from isothermal HTL. Therefore, the $\mathrm{N}$ that is retained in the biocrude is concentrated in some of the heavier compounds. We speculate that the high-molecular weight compounds identified in the biocrude from fast HTL with high loading are residual cellular components that were not readily soluble in the aqueous phase. Since isothermal HTL is the most severe of the reaction conditions examined, oligomerization and/or condensation reactions involving dissolved protein components that could produce higher molecular weight compounds may be 
more likely, explaining the large number of $\mathrm{N}$-containing high molecular weight compounds. One likely example of such a reaction was postulated by Sudasinghe et al. and is depicted in Figure 2: the formation of amides from reactions of carboxylic acids with ammonia (a water-soluble product of protein decomposition). ${ }^{14}$

Sodium- and Sulfur-Containing Compounds

FT-ICR MS analysis identified several compounds in the products of HTL that contain Na and/or S, as Figures $13,14,15$, S11 and S12 indicate. Such compounds are of interest because they are potential catalyst poisons in an algal biorefinery. To the best of our knowledge, this is the first detailed report including identification of molecular formulae containing $\mathrm{Na}$ and $\mathrm{S}$ in both the aqueous phase and biocrude products of algal $\mathrm{HTL}$. Naand S-containing compounds were preferentially ionized by different ESI modes; positive ESI did not identify any S-containing compounds, but it identified more Na-containing compounds than did negative ESI. Identification of S-containing compounds solely with negative ESI indicates that the $\mathrm{S}$ present in molecules with molecular weights $>200$ in both the aqueous phase and biocrude samples is likely incorporated into acidic compounds. Amino acids and thiols are examples of acidic S-containing compounds.

Of the aqueous phase samples, the most Na-containing compounds were identified in the aqueous phase from fast HTL with the low loading (2938, followed by 2384 and 1783, the aqueous phase from the fast, high loading and isothermal HTL conditions, respectively). The fast, low loading HTL reaction condition was also the only one for which compounds with $2 \mathrm{Na}$ atoms were identified. Such compounds were identified in both the aqueous phase and biocrude products, as Figure S11 illustrates. Figures 13 and 14 depict the $\mathrm{Na} / \mathrm{C}$ ratios with respect to the average molecular weights of the aqueous phase and biocrude compounds containing $\mathrm{Na}$.

These figures reveal two distinct "bands" for the products from fast HTL with low loading. The Na-containing compounds in the biocrude may include mono- or di-sodium organo-metallic salts with sufficient hydrocarbon character to be soluble in dichloromethane. Sudasinghe et al. reported adducts of $\mathrm{Na}$ with acylglyerol lipids in biocrudes from low-temperature isothermal $\mathrm{HTL},{ }^{15}$ so similar products may also be present in the biocrude samples examined in the present work. The presence of $\mathrm{Na}$ in fuels can be problematic, ${ }^{44}$ so upgrading of biocrudes from HTL of microalgae would need to include removal of $\mathrm{Na}$ in addition to $\mathrm{N}, \mathrm{O}$, and $\mathrm{S}$.

Figure 15 depicts the $\mathrm{S} / \mathrm{C}$ atomic ratios with respect to the average molecular weight of the S-containing compounds in the aqueous phase samples from HTL. All of the compounds contain just a single $S$ atom. The aqueous phase from fast HTL with high loading appears to contain the fewest compounds with $\mathrm{S} / \mathrm{C}$ ratios $>0.1$. Few S-containing compounds were identified in the biocrude samples from HTL of Nannochloropsis sp. in this study (83, 27, and 54 from fast, low loading, fast, high loading, and isothermal HTL, respectively). Figure S12 in the SI shows that the S-containing compounds present were most abundant at the lower molecular weights. The 
biocrude contained about $0.5 \mathrm{wt} \% \mathrm{~S}$, so much of this sulfur seems to exist in smaller $(\mathrm{MW}<200)$ molecules not detected by FT-ICR MS.

\section{Herbicides as By-Products}

Given the wealth of data obtained for molecular formulae of reaction products, we searched for molecular formulae of known herbicides in the aqueous phase samples. The molecular formulae and DBEs for imazamethabenz $\left(\mathrm{C}_{15} \mathrm{H}_{18} \mathrm{~N}_{2} \mathrm{O}_{3}\right)$, imazaquin $\left(\mathrm{C}_{17} \mathrm{H}_{17} \mathrm{~N}_{3} \mathrm{O}_{3}\right)$, and imazapyr $\left(\mathrm{C}_{13} \mathrm{H}_{15} \mathrm{~N}_{3} \mathrm{O}_{3}\right)$ matched those of products in the aqueous phase. Although we do not know for certain whether these herbicides are, in fact, the species in the samples analyzed by FT-ICR MS, the matching molecular formulae and DBEs provide circumstancial evidence.

From a sustainability point of view, it would be preferable to use the aqueous phase as a $\mathrm{N}$ and $\mathrm{P}$ source for algae cultivation. However, previous studies indicated toxicity effects when the aqueous phase is used to grow algae. ${ }^{45}$ The possible presence of known herbicides may shed some light on why these toxic effects are observed. Some kind of treatment, perhaps biological ${ }^{46}$ or thermochemical, ${ }^{47}$ can likely mitigate the toxicity of the aqueous phase for algae cultivation.

\section{Summary and Conclusions}

This study provides the first FT-ICR MS characterization of the aqueous phase and biocrude products from fast HTL of microalgae. It also provides the first comparisons between fast and isothermal HTL at identical loadings and between different reactor mass loadings for fast HTL. Fast HTL with low mass loading produced higher biocrude yields than did isothermal HTL and fast HTL with high loading. However, the quality of biocrude produced via fast HTL with low loading appears to be less desirable than the biocrude produced via isothermal HTL or fast HTL with high loading. Closely related to this trade-off between quality and quantity is the trade-off between the desirable recovery of $\mathrm{C}$ and the undesirable recovery of heteroatoms in the biocrude. Fast HTL with the low loading gave the highest $\mathrm{C}$ recovery to the biocrude, but it also gave the highest recovery of $\mathrm{N}$ and $\mathrm{S}$ to the biocrude, which would necessitate more aggressive upgrading in an industrial implementation of this process.

The trade-offs associated with elemental recovery extend to aqueous phase products as well. HTL with high reactor loading (including both fast and isothermal $\mathrm{HTL}$ ) leads to high recovery of $\mathrm{N}$ in the aqueous phase, which would be desirable for recycling $\mathrm{N}$ for algae cultivation. However, HTL with high reactor loading also promotes high recovery of $C$ in the aqueous phase, which diverts $C$ away from the biocrude. The trade-offs identified here provide many opportunities for the optimization of HTL processing conditions.

These trade-offs exist because rapid heating, mass loading, and reaction severity promote different reaction paths. For example, during HTL at the low loading, the algae and products derived therefrom experienced a higher 
effective concentration in the liquid water phase at reaction conditions because more of the water is partitioned to the vapor phase at this condition.

High molecular weight compounds in the aqueous phase product from fast HTL with high loading are consistent with the molecular formulae and saturation levels of polypeptide chains, indicating that solubilization of these peptides and/or polypeptides into liquid water takes place very quickly. Far fewer high molecular weight compounds consistent with polypeptides are identified in the aqueous phase products of fast HTL with low loading and isothermal HTL, which may indicate that such polypeptides are subject to decomposition and other reactions at these other conditions. This finding also suggests that further research is needed to better understand the effects of mass loading, especially for HTL at very short times and with rapid heating.

Analysis using FT-ICR MS revealed that biocrudes from fast HTL contain several compounds with no $\mathrm{N}$ but 3- $7 \mathrm{O}$ atoms. These compounds are likely free fatty acids and/or oligomerized or polymerized fatty acids. All O-containing compounds present in the biocrude from isothermal HTL (identified using positive ESI) also contain $\mathrm{N}$, possibly indicating that isothermal HTL provides ample time for reactions between O-containing compounds and $\mathrm{N}$-containing compounds (likely including the formation of amides from carboxylic acids with organic amines or ammonia). This idea is reinforced by the observation that many of the high molecular weight compounds in the biocrude from isothermal HTL are basic, while many of the high molecular weight compounds present in the biocrudes produced via fast HTL are more acidic. However, analysis by negative ESI revealed many compounds with $2 \mathrm{O}$ atoms and no $\mathrm{N}$ atoms in the biocrude samples from all three reaction conditions, which likely indicates that reactions between $\mathrm{N}$ - and $\mathrm{O}$ - containing compounds do not consume all fatty acids, even after isothermal HTL.

The detailed data provided by FT-ICR MS analysis facilitated the tentative identification of herbicides in the aqueous phase. To the best of our knowledge, no other studies have suggested specific compounds in the aqueous phase products from HTL that may contribute to the toxic effect of aqueous phase on algae cultivation. This information could be especially helpful for informing the treatment of the aqueous phase products or the genetic engineering of bacteria and/or algae that are capable of tolerating, or even metabolizing, these compounds.

\section{Acknowledgments}

This contribution was identified by Michael Timko (Worcester Polytechnic Institute) as the Best Presentation in the session "Reaction Engineering of Biomass and Hydrocarbons in Supercritical Water" of the 2014 AIChE Annual Meeting in Atlanta, GA.

The authors thank Hao Chen for his experimental assistance and Michael Nelson for his expertise in aqueous phase analysis. The authors also thank the National Science Foundation (Grant EFRI-0937992), the University of 
Michigan Rackham Graduate School, and the University of Michigan College of Engineering for financial support. Julia Faeth acknowledges that this material is based on work supported by the National Science Foundation Graduate Student Research Fellowship under Grant DGE 1256260. The Venn Diagrams depicted in this work were supported by software from the W.R. Wiley Environmental Molecular Science Laboratory, a national scientific user facility sponsored by the U.S. Department of Energy's Office of Biological and Environmental Research and located at PNNL. PNNL is operated by Battelle Memorial Institute for the U.S. Department of Energy under contract DE-AC05-76RL0 1830. Work performed at the National High Magnetic Field Laboratory was supported by the National Science Foundation through DMR-1157490, Florida State University, and the State of Florida.

\section{Literature Cited}

1 Chisti Y. Constraints to commercialization of algal fuels. Journal of Biotechnology. 2013;167:201-214.

2 Malcata FX. Microalgae and biofuels: a promising partnership? Trends in Biotechnology. 2011;29:542-549.

3 Faeth JL, Valdez PJ, Savage PE. Fast Hydrothermal Liquefaction of Nannochloropsis sp. To Produce Biocrude. Energy \& Fuels. 2013;27:1391-1398.

4 Bach QV, Sillero MV, Tran KQ, Skjermo J. Fast hydrothermal liquefaction of a Norwegian macro-alga: Screening tests. Algal Research. 2014;6:271-276.

5 Valdez PJ, Nelson MC, Faeth JL, Wang HY, Lin XN, Savage PE. Hydrothermal Liquefaction of Bacteria and Yeast Monocultures. Energy \& Fuels. 2014;28:67-75.

6 Marshall AG, Hendrickson CL, Jackson GS. Fourier transform ion cyclotron resonance mass spectrometry: a primer. Mass Spectrometry Reviews. 1998;17:1-35.

7 Marshall AG, Rodgers RP. Petroleomics: The Next Grand Challenge for Chemical Analysis Petroleum and Mass Spectrometry: Divergent. Accounts of Chemical Research. 2004;37:53-59.

8 Marshall AG, Rodgers RP. Petroleomics: chemistry of the underworld. Proceedings of the National Academy of Sciences of the United States of America. 2008;105:18090-18095.

9 Gaspar A, Zellermann E, Lababidi S, Reece J, Schrader W. Impact of different ionization methods on the molecular assignments of asphaltenes by FT-ICR mass spectrometry. Analytical Chemistry. 2012;84:52575267.

10 Pan Y. Acidic and Neutral Polar NSO Compounds in Heavily Biodegraded Oils Characterized by Negative-lon ESI FT-ICR MS. Energy \& Fuels. 2013;27:2960-2973. 
1 Poetz S, Hors B, Wilkes H. Maturity-Driven Generation and Transformation of Acidic Compounds in the Organic-Rich Posidonia Shale as Revealed by Electrospray lonization Fourier Transform lon Cyclotron Resonance Mass Spectrometry. Energy \& Fuels. 2014;28:4877-4888.

2 Ruddy BM, Huettel M, Kostka JE, et al. Targeted Petroleomics: Analytical Investigation of Macondo Well Oil Oxidation Products from Pensacola Beach. Energy \& Fuels. 2014;28:4043-4050.

3 Levine RB, Sierra COS, Hockstad R, Obeid W, Hatcher PG, Savage PE. The Use of Hydrothermal Carbonization to Recycle Nutrients in Algal Biofuel Production. Environmental Progress \& Sustainable Energy. 2013;32:962-975.

4 Sudasinghe N, Dungan B, Lammers P, et al. High resolution FT-ICR mass spectral analysis of bio-oil and residual water soluble organics produced by hydrothermal liquefaction of the marine microalga Nannochloropsis salina. Fuel. 2014;119:47-56.

5 Sudasinghe N, Reddy H, Csakan N, Deng S, Lammers P, Schaub T. Temperature-Dependent Lipid Conversion and Nonlipid Composition of Microalgal Hydrothermal Liquefaction Oils Monitored by Fourier Transform Ion Cyclotron Resonance Mass Spectrometry. BioEnergy Research. 2015. Accepted Manuscript, DOI $10.1007 /$ s12155-015-9635-9.

6 Sanguineti MM, Hourani N, Witt M, Sarathy SM, Thomsen L, Kuhnert N. Analysis of impact of temperature and saltwater on Nannochloropsis salina bio-oil production by ultra high resolution APCI FT-ICR MS. Algal Research. 2015;9:227-235.

7 Jarvis JM, McKenna AM, Hilten RN, Das KC, Rodgers RP, Marshall AG. Characterization of Pine Pellet and Peanut Hull Pyrolysis Bio-oils by Negative-lon Electrospray lonization Fourier Transform Ion Cyclotron Resonance Mass Spectrometry. Energy \& Fuels. 2012;26:3810-3815.

8 Bi Y, Wang G, Shi Q, Xu C, Gao J. Compositional Changes during Hydrodeoxygenation of Biomass Pyrolysis Oil. Energy \& Fuels. 2014;28:2571-2580.

9 Chiaberge S, Leonardis I, Fiorani T, Cesti P, Reale S, De Angelis F. Bio-Oil from Waste: A Comprehensive Analytical Study by Soft-lonization FTICR Mass Spectrometry. Energy \& Fuels. 2014;28:2019-2026.

0 Holguin FO, Schaub T. Characterization of microalgal lipid feedstock by direct-infusion FT-ICR mass spectrometry. Algal Research. 2013;2:43-50.

1 Kekäläinen T, Venäläinen T, Jänis J. Characterization of Birch Wood Pyrolysis Oils by Ultrahigh- Resolution Fourier Transform Ion Cyclotron Resonance Mass Spectrometry: Insights into Thermochemical Conversion. Energy \& Fuels. 2014;28:4596-4602. 
2 Kumar S, Hablot E, Moscoso JLG, et al. Polyurethanes preparation using proteins obtained from microalgae. Journal of Materials Science. 2014;49:7824-7833.

3 Leonardis I, Chiaberge S, Fiorani T, et al. Characterization of bio-oil from hydrothermal liquefaction of organic waste by NMR spectroscopy and FTICR mass spectrometry. ChemSusChem. 2013;6:160-167.

4 Tessarolo NS, Silva RC, Vanini G, et al. Assessing the chemical composition of bio-oils using FT-ICR mass spectrometry and comprehensive two-dimensional gas chromatography with time-of-flight mass spectrometry. Microchemical Journal. 2014;117:68-76.

5 Nyakas A, Han J, Headley JV, Borchers CH. Comprehensive Analysis of Oil Sands Processed Water by DirectInfusion Fourier-Transform Ion Cyclotron Resonance Mass Spectrometry with and without Offline UHPLC Sample Prefractionation. Environmental Science \& Technology. 2013;47:4471-4479.

6 Valdez PJ, Nelson MC, Wang HY, Lin XN, Savage PE. Hydrothermal liquefaction of Nannochloropsis sp.: Systematic study of process variables and analysis of the product fractions. Biomass \& Bioenergy. 2012;46:317331.

7 Brown TM, Duan P, Savage PE. Hydrothermal Liquefaction and Gasification of Nannochloropsis sp. Energy \& Fuels. 2010;24:3639-3646.

8 Kaiser NK, Savory JJ, McKenna AM, Quinn JP, Hendrickson CL, Marshall AG. Electrically compensated Fourier transform ion cyclotron resonance cell for complex mixture mass analysis. Analytical Chemistry. 2011;83:6907-6910.

9 Blakney GT, Hendrickson CL, Marshall AG. Predator data station: A fast data acquisition system for advanced FT-ICR MS experiments. International Journal of Mass Spectrometry. 2011;306:246-252.

0 Xian F, Hendrickson CL, Blakney GT, Beu SC, Marshall AG. Automated broadband phase correction of Fourier transform ion cyclotron resonance mass spectra. Analytical Chemistry. 2010;82:8807-8812.

1 Xian F, Corilo YE, Hendrickson CL, Marshall AG. Baseline correction of absorption-mode Fourier transform ion cyclotron resonance mass spectra. International Journal of Mass Spectrometry. 2012;325-327:67-72.

2 Ledford EB, Rempel DL, Gross ML. Space charge effects in Fourier transform mass spectrometry. Mass calibration. Analytical Chemistry. 1984;56:2744-2748.

3 Savory JJ, Kaiser NK, Mckenna AM, et al. Measurement Accuracy with a Walking Calibration Equation. Analytical Chemistry. 2011;83:1732-1736. 
4 Kendrick E. A Mass Scale Based on $\mathrm{CH} 2=14.0000$ for High Resolution Mass Spectrometry of Organic Compounds. Analytical Chemistry. 1963;35:2146-2154.

5 Corilo YE. PetroOrg Software; Florida State University; All Rights Reserved. Date Accessed 8 July 2015.

6 Armbruster U, Martin A, Krepel A. Partial oxidation of propane in sub- and supercritical water. The Journal of Supercritical Fluids. 2001;21:233-243.

7 Annamalai K, Sweeten JM, Ramalingam SC. Estimation of Gross Heating Values of Biomass Fuels. Transaction of the ASAE. 1987;30:1205-1208.<smiles>C1CC1</smiles>

8 Garcia-Moscoso JL, Teymouri A, Kumar S. Kinetics of Peptides and Arginine Production from Microalgae (Scenedesmus sp.) by Flash Hydrolysis. Industrial \& Engineering Chemistry Research. 2015;54:2048-2058.

9 Pacific Northwest National Laboratory Venn Diagram Plotter - Pan-Omics Research. Date Accessed 10 February 2015.

0 Hughey CA, Rodgers RP, Marshall AG, Qian K, Robbins WK. Identification of NSO Compounds in Crude Oils of Different Geochemical Origins by Negative Ion Electrospray Fourier Transform Ion Cyclotron Resonance Mass Spectrometry. Organic Geochemistry. 2002;33:743-759.

1 Lu Y, Levine RB, Savage PE. Fatty Acids for Nutraceuticals and Biofuels from Hydrothermal Carbonization of Microalgae. Industrial \& Engineering Chemistry Research. 2015;54:4066-4071.

2 Krevelen DW. Graphical-statistical method for the study of structure and reaction processes of coal. Fuel. 1950;29:269-284.

3 Kim S, Kramer RW, Hatcher PG. Graphical method for analysis of ultrahigh-resolution broadband mass spectra of natural organic matter, the van Krevelen diagram. Analytical Chemistry. 2003;75:5336-5344.

4 Barker J, Cook S, Richards P. Sodium Contamination of Diesel Fuel, its Interaction with Fuel Additives and the Resultant Effects on Filter Plugging and Injector Fouling. SAE International Journal of Fuels and Lubricants. 2013;6:826-838.

5 Biller $\mathrm{P}$, Ross $\mathrm{AB}$, Skill SC, et al. Nutrient recycling of aqueous phase for microalgae cultivation from the hydrothermal liquefaction process. Algal Research. 2012;1:70-76.

6 Nelson M, Zhu L, Thiel A, et al. Microbial utilization of aqueous co-products from hydrothermal liquefaction of microalgae Nannochloropsis oculata. Bioresource Technology. 2013;136:522-528. 
7 Elliott DC, Hart TR, Schmidt AJ, et al. Process development for hydrothermal liquefaction of algae feedstocks in a continuous-flow reactor. Algal Research. 2013;2:445-454.
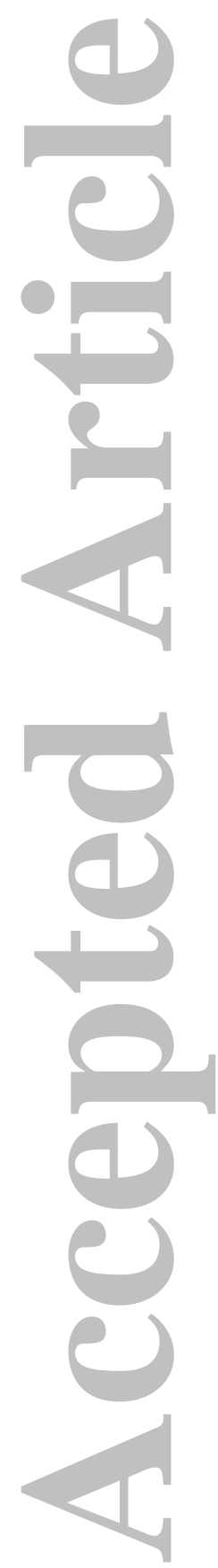
Table 1

\begin{tabular}{|l|c|c|c|}
\hline & Fast, Low Loading & Fast, High Loading & Isothermal \\
\hline Setpoint Temperature & 600 & 600 & 300 \\
\hline Reaction Time (min) & 1 & 1 & 20 \\
\hline Maximum Reaction Temperature & $186 \pm 14$ & $186 \pm 14$ & $279 \pm 1$ \\
\hline Log Reaction Ordinate (RO) & 2.01 & $11.9 \pm 3.7$ & $62.9 \pm 0.5$ \\
\hline $\begin{array}{l}\text { Pressure at Maximum Reaction Tem- } \\
\text { perature (bar) }\end{array}$ & $11.9 \pm 3.7$ & $0.306 \pm 0.006$ & $0.208 \pm 0.001$ \\
\hline $\begin{array}{l}\text { Headspace Volume Fraction at Maxi- } \\
\text { mum Reaction Temperature }\end{array}$ & $0.888 \pm 0.002$ & 0.91 \\
\hline
\end{tabular}
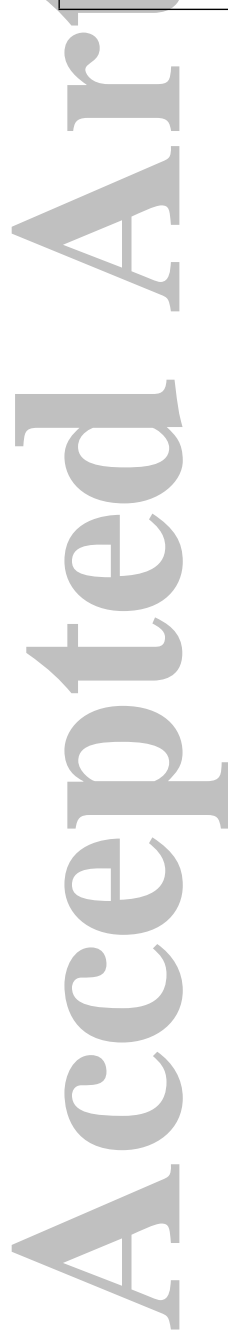
Table 2

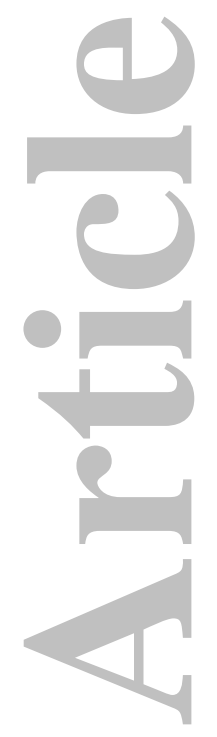

\begin{tabular}{|c|c|c|c|}
\hline & Fast, Low Loading & Fast, High Loading & Isothermal \\
\hline Biocrude & $44.9 \pm 1.0$ & $36.9 \pm 0.1$ & $37.5 \pm 0.9$ \\
\hline Aqueous & $49.0 \pm 10.2$ & $45.9 \pm 7.1$ & $49.8 \pm 3.3$ \\
\hline Solid & $10.2 \pm 0.5$ & $12.4 \pm 1.4$ & $5.4 \pm 0.4$ \\
\hline Gas & $4.3 \pm 0.4$ & $1.6 \pm 0.2$ & $1.4 \pm 0.3$ \\
\hline Total & $108.5 \pm 11.3$ & $100.7 \pm 4.5$ & $96.7 \pm 0.3$ \\
\hline
\end{tabular}

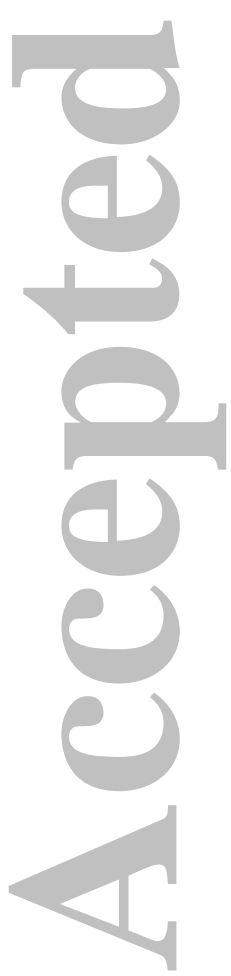


Table 3

\begin{tabular}{|c|c|c|c|}
\hline & Fast, Low Loading & Fast, High Loading & Isothermal \\
\hline $\mathrm{H}_{2}$ & $0.035 \pm 0.001$ & $0.009 \pm 0.001$ & $0.0002 \pm 0.00002$ \\
\hline $\mathrm{CO}$ & $0.120 \pm 0.024$ & $0.075 \pm 0.043$ & $0.002 \pm 0.0004$ \\
\hline $\mathrm{CH}_{4}$ & $0.046 \pm 0.0004$ & $0.012 \pm 0.0003$ & $0.001 \pm 0.0001$ \\
\hline $\mathrm{CO}_{2}$ & $0.857 \pm 0.080$ & $0.301 \pm 0.011$ & $0.317 \pm 0.075$ \\
\hline $\mathrm{C}_{2} \mathrm{H}_{4}$ & $0.043 \pm 0.008$ & $0.009 \pm 0.001$ & Not Detected \\
\hline $\mathrm{C}_{2} \mathrm{H}_{6}$ & $0.013 \pm 0.0001$ & $0.004 \pm 0.0005$ & Not Detected \\
\hline
\end{tabular}


Table 4

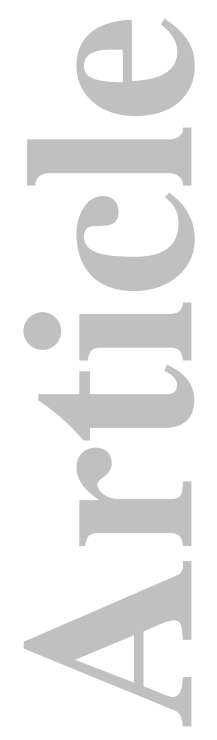

\begin{tabular}{|c|c|c|c|c|}
\hline & C & H & N & S \\
\hline Fast, Low Loading & 22.5 & 7.00 & 6.30 & 0.48 \\
\hline Fast, High Loading & 31.0 & 7.49 & 9.09 & 0.49 \\
\hline Isothermal & 29.5 & 7.59 & 7.79 & 0.46 \\
\hline
\end{tabular}

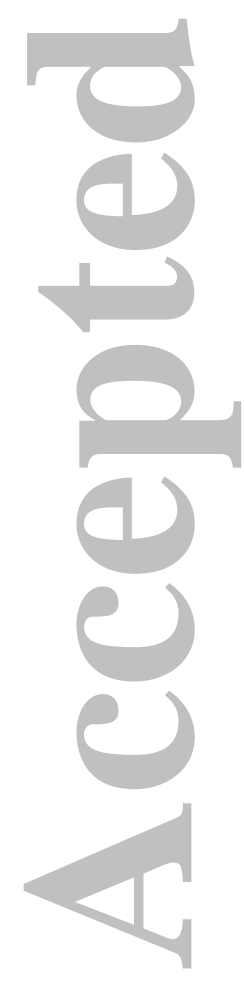


Table 5

\begin{tabular}{|c|c|c|c|c|c|c|}
\hline & C & $\mathrm{H}$ & $\mathrm{N}$ & $\mathrm{S}$ & $\mathrm{O}$ & $\mathrm{HHV}(\mathrm{MJ} / \mathrm{kg})$ \\
\hline Fast, Low Loading & 66.7 & 8.78 & 8.21 & 0.70 & 15.6 & 32.5 \\
\hline Fast, High Loading & 70.2 & 9.38 & 5.76 & 0.68 & 14.0 & 34.5 \\
\hline Isothermal & 69.0 & 9.22 & 6.10 & 0.51 & 15.1 & 33.7 \\
\hline
\end{tabular}
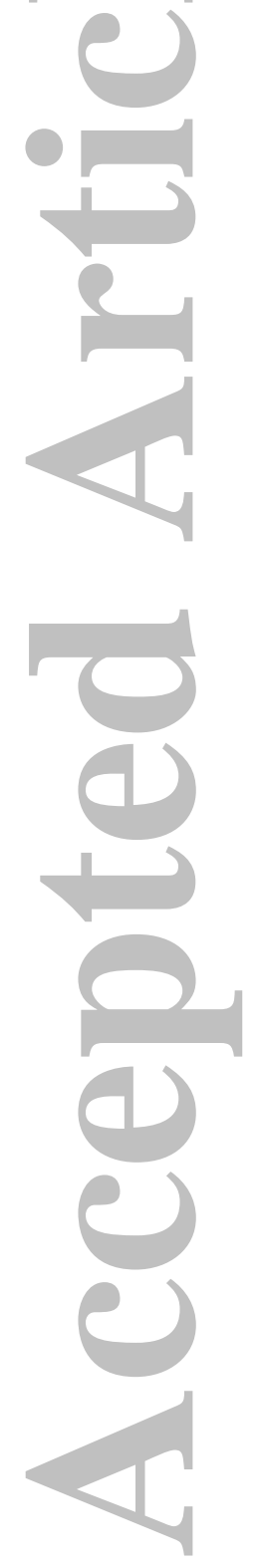


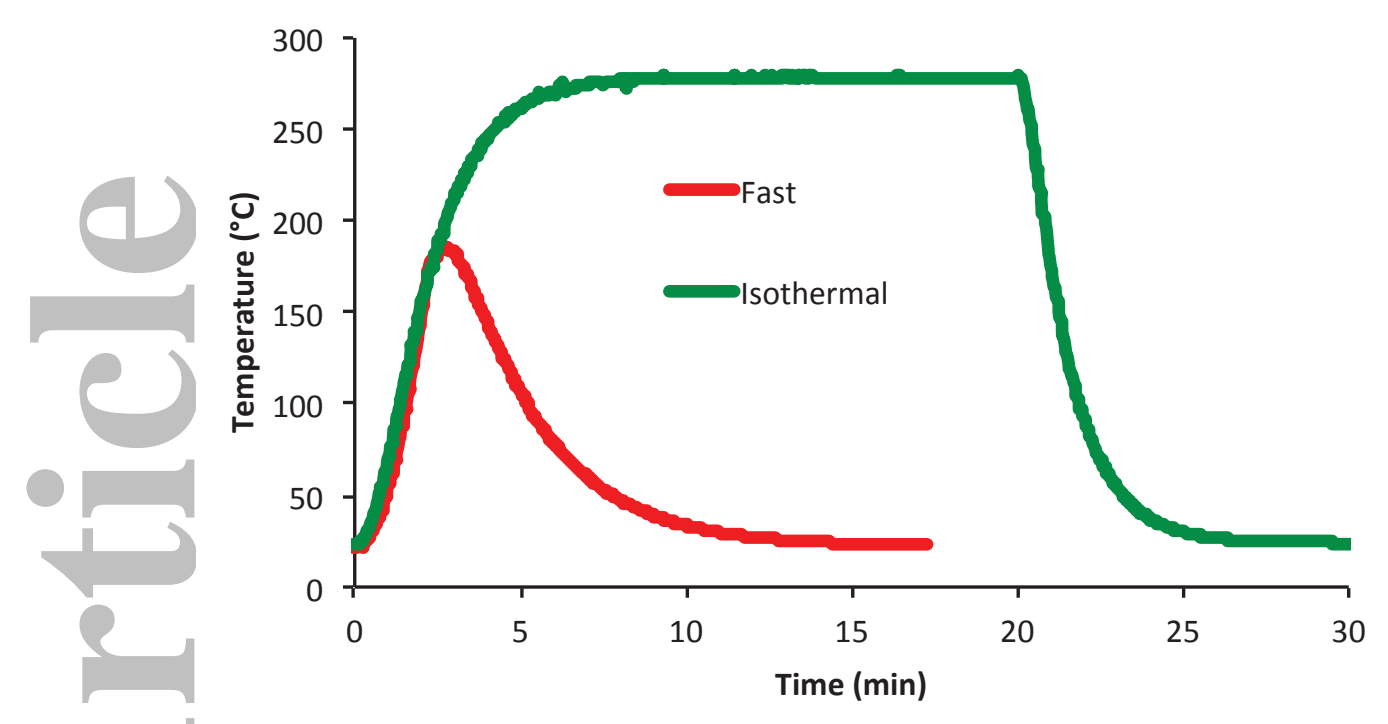

Figure 1 


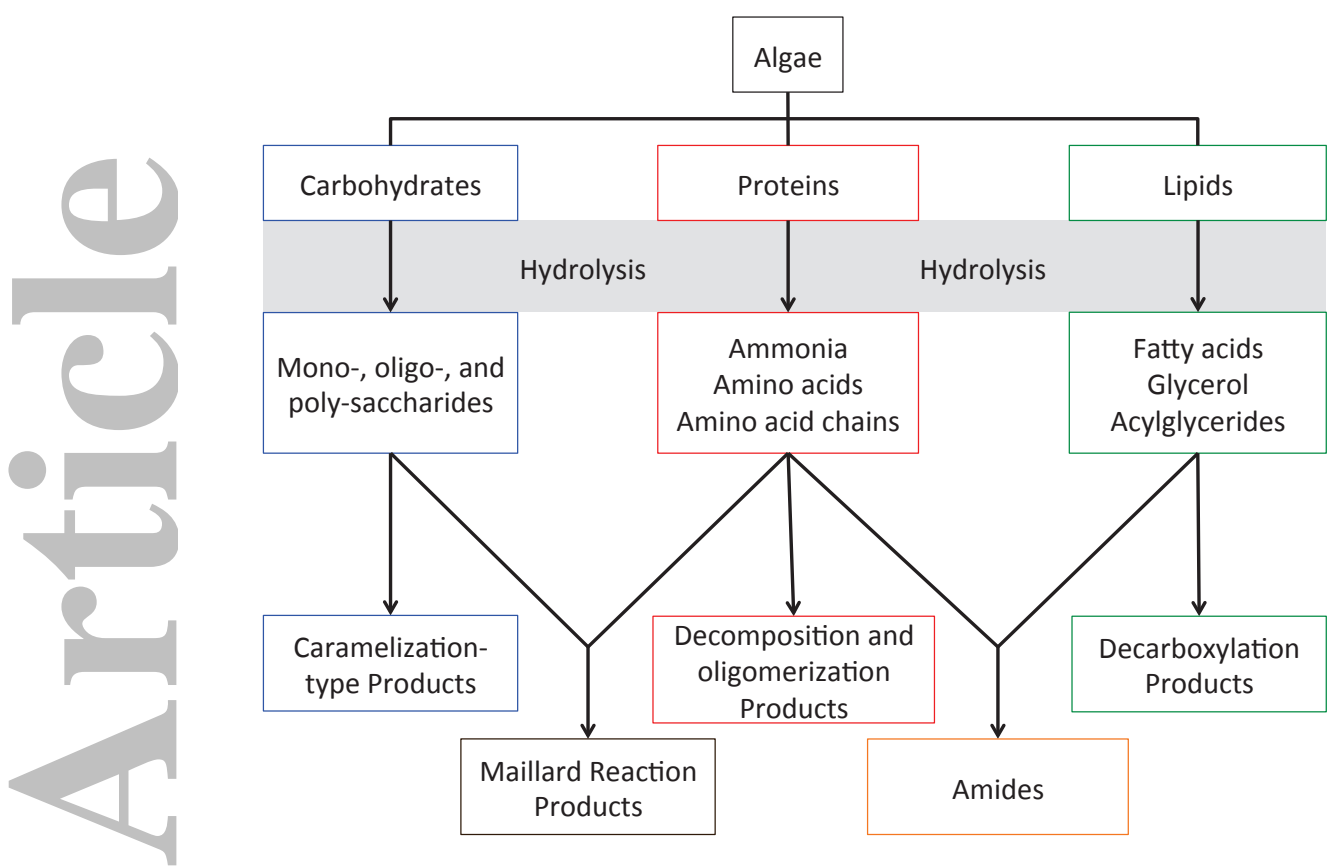

Figure 2

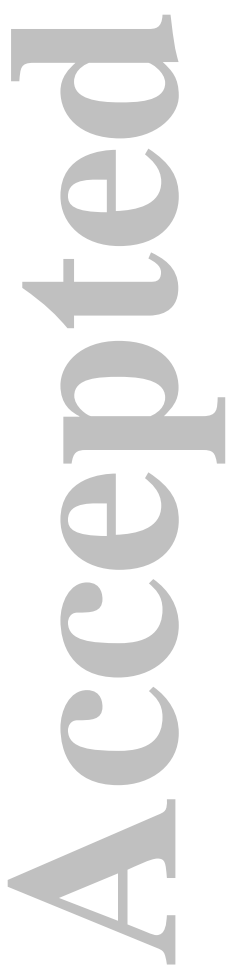




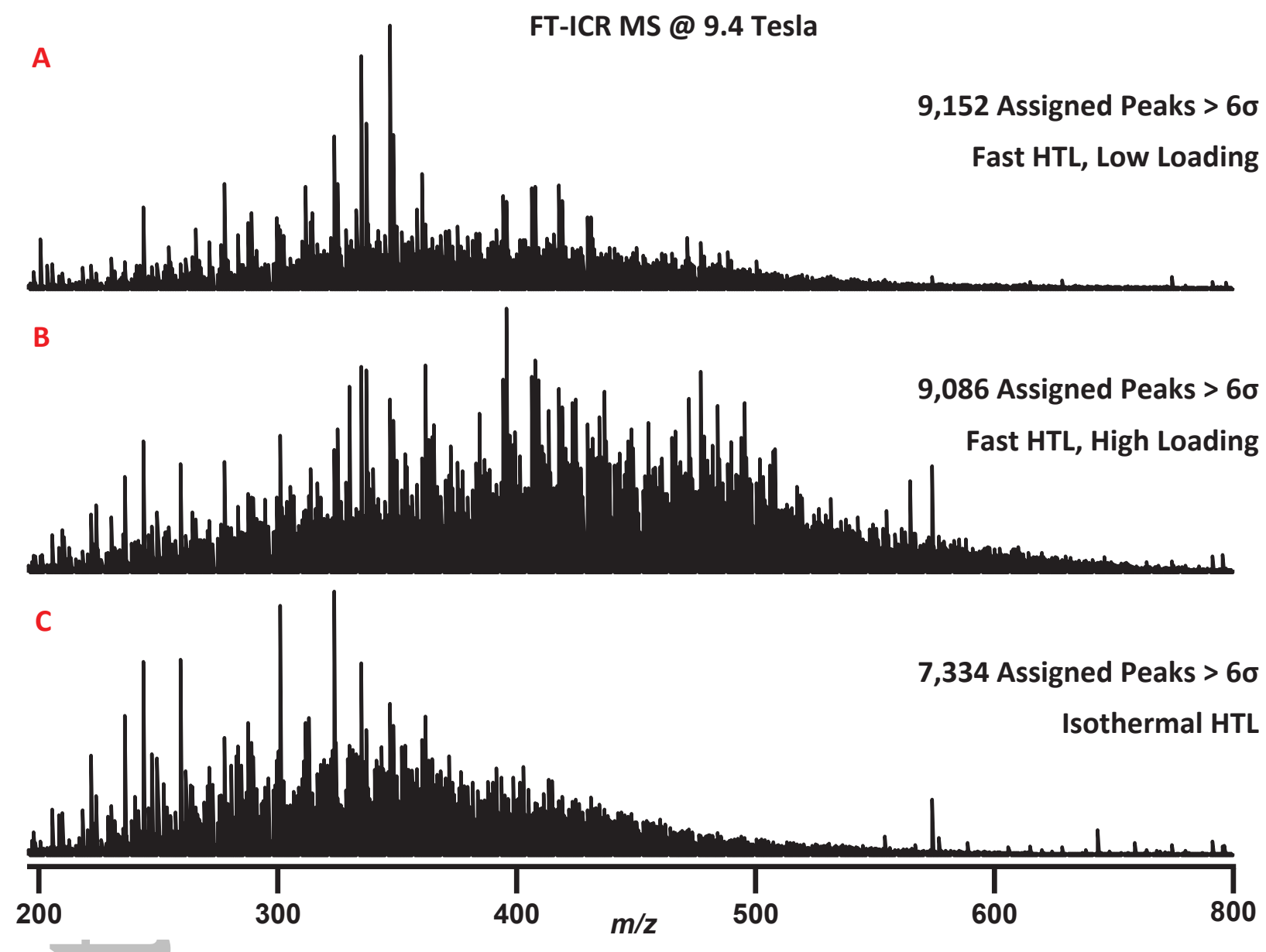

Figure 3 


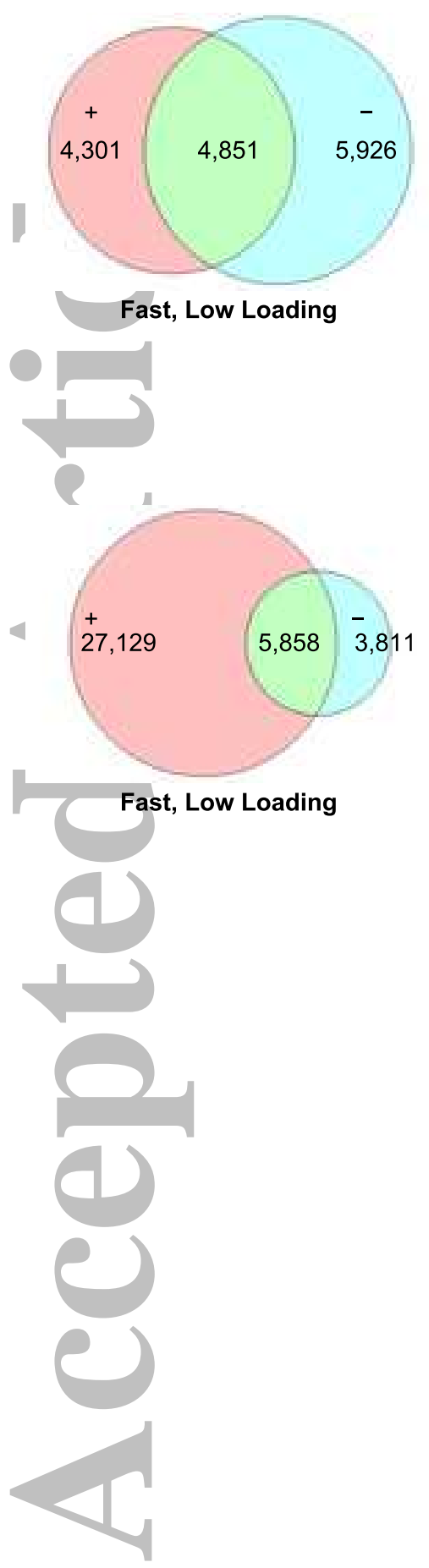

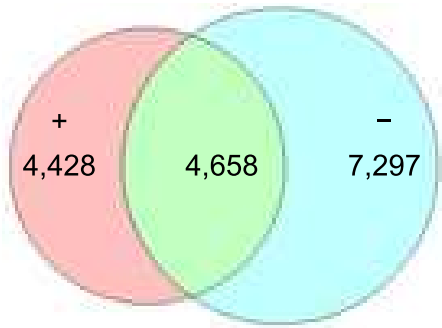

Fast, High Loading

(a) Aqueous Phase Samples

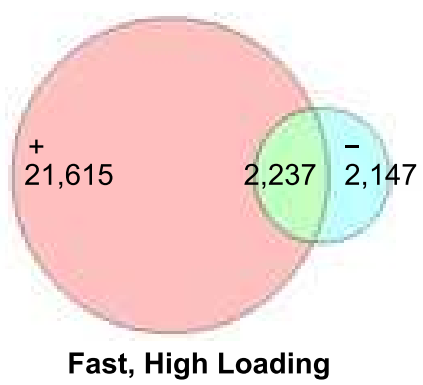

Fast, High Loading

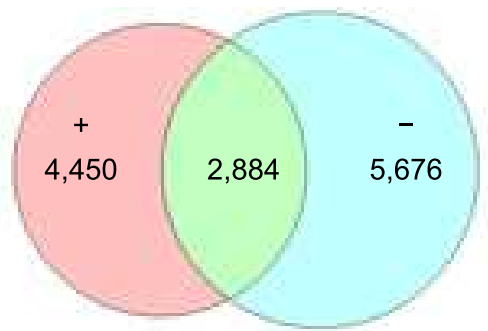

Isothermal

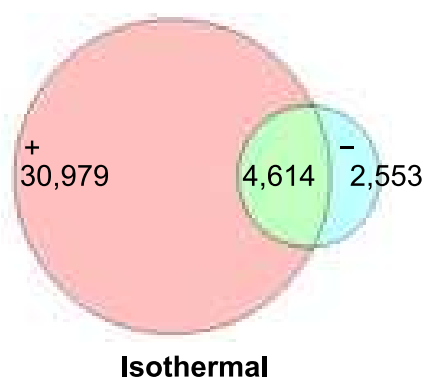

(b) Biocrude Samples

Figure 4 


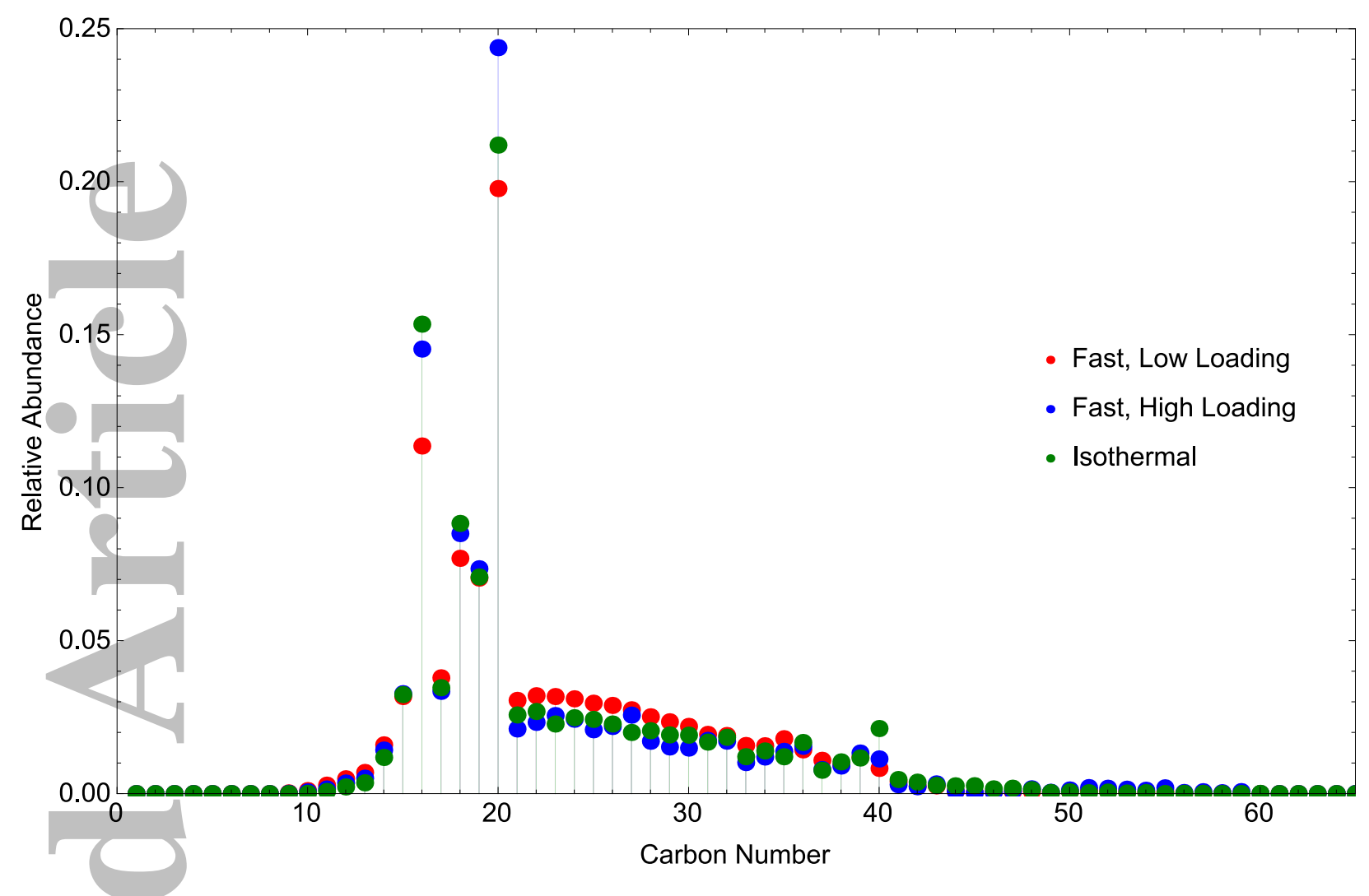

Figure 5 


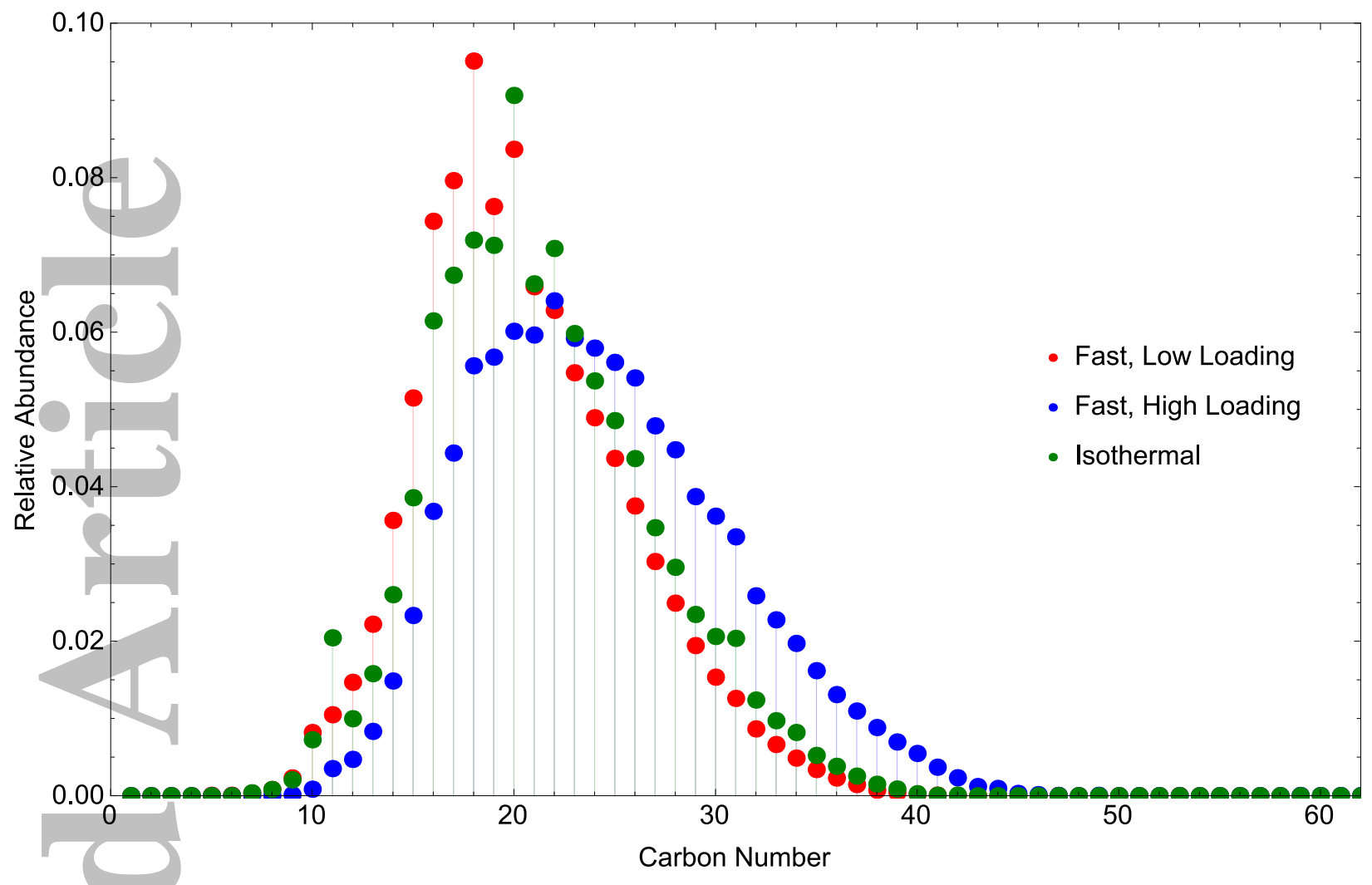

Figure 6 

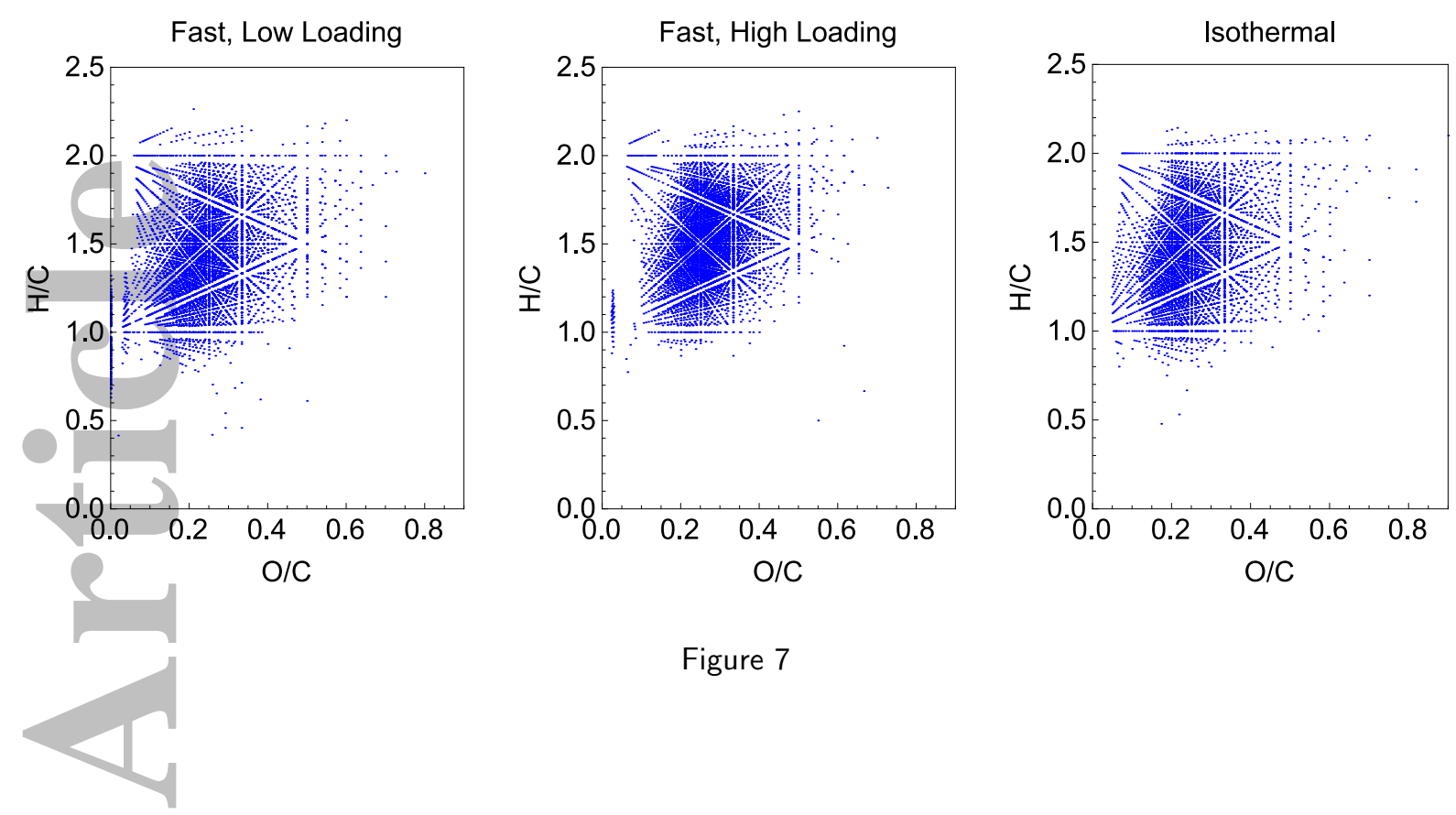

Figure 7

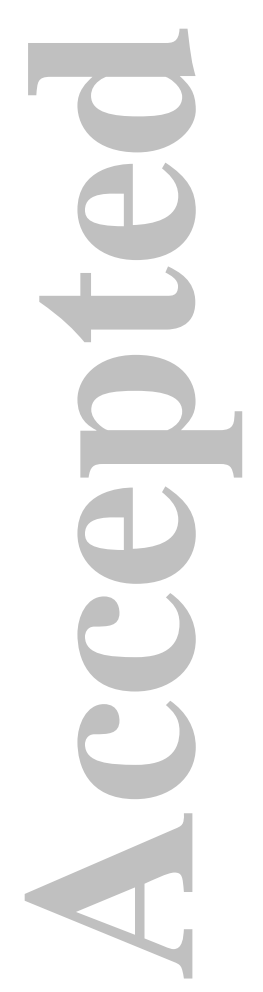



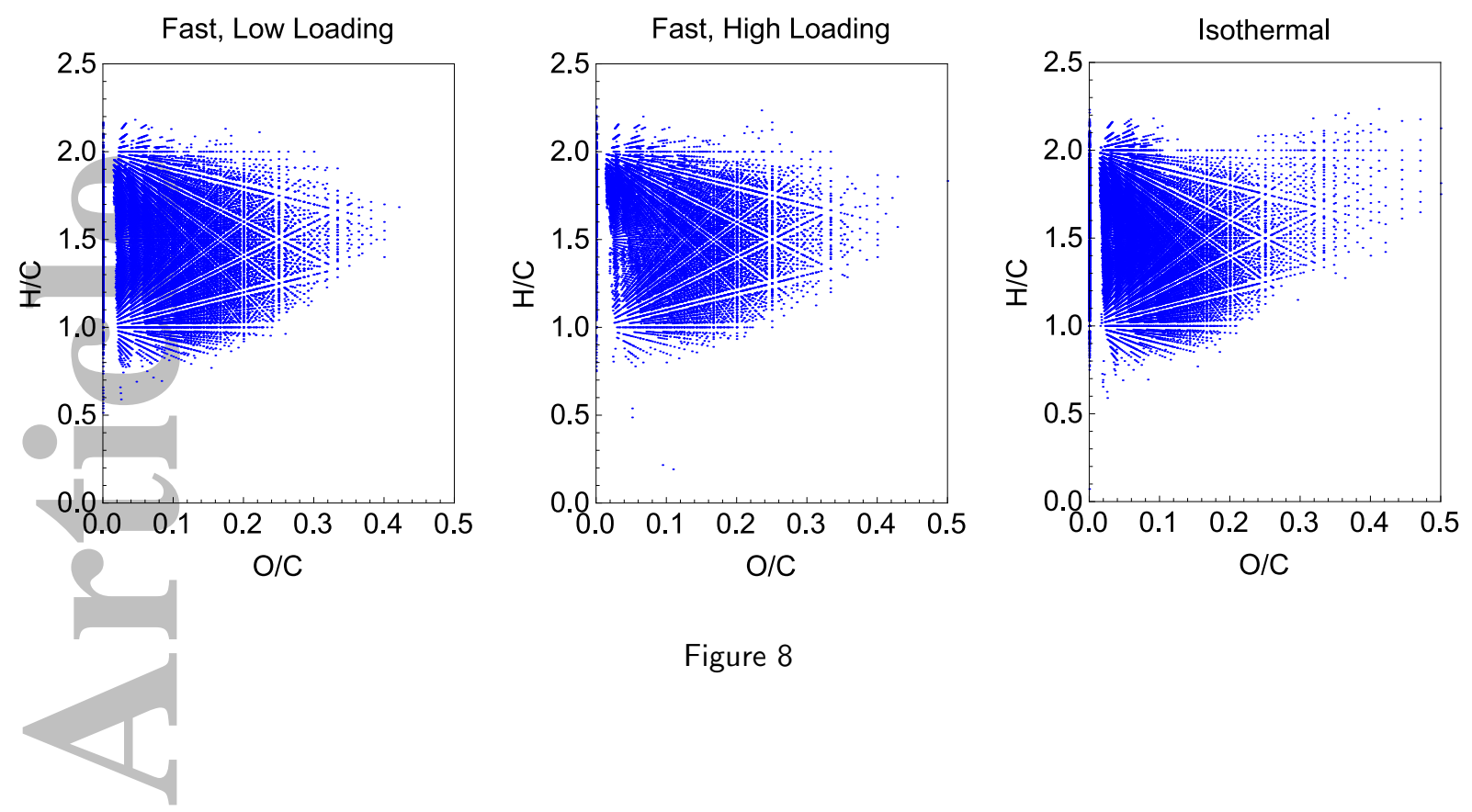

Figure 8

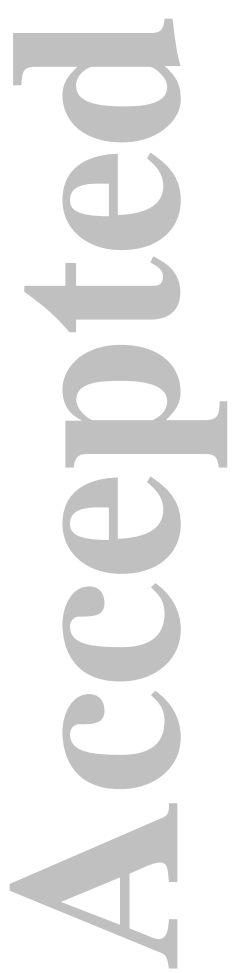




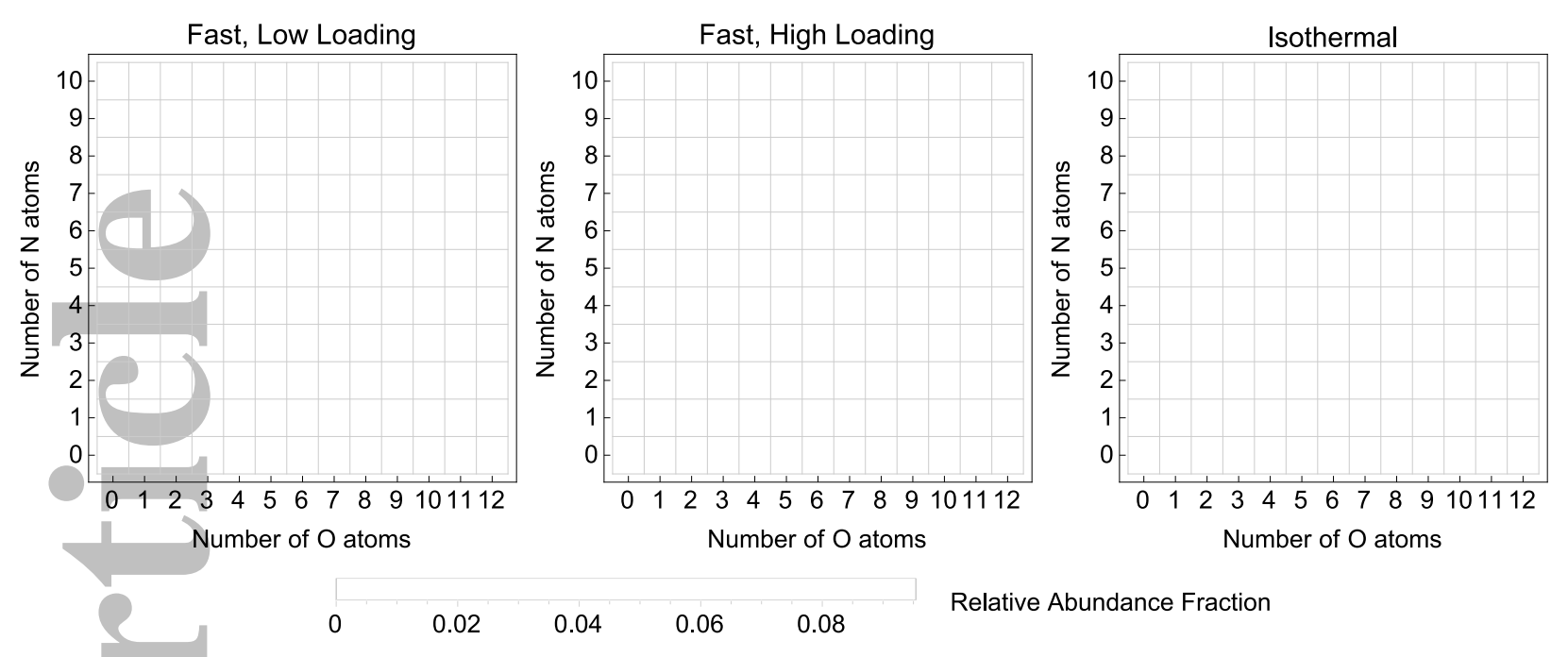

Figure 9 

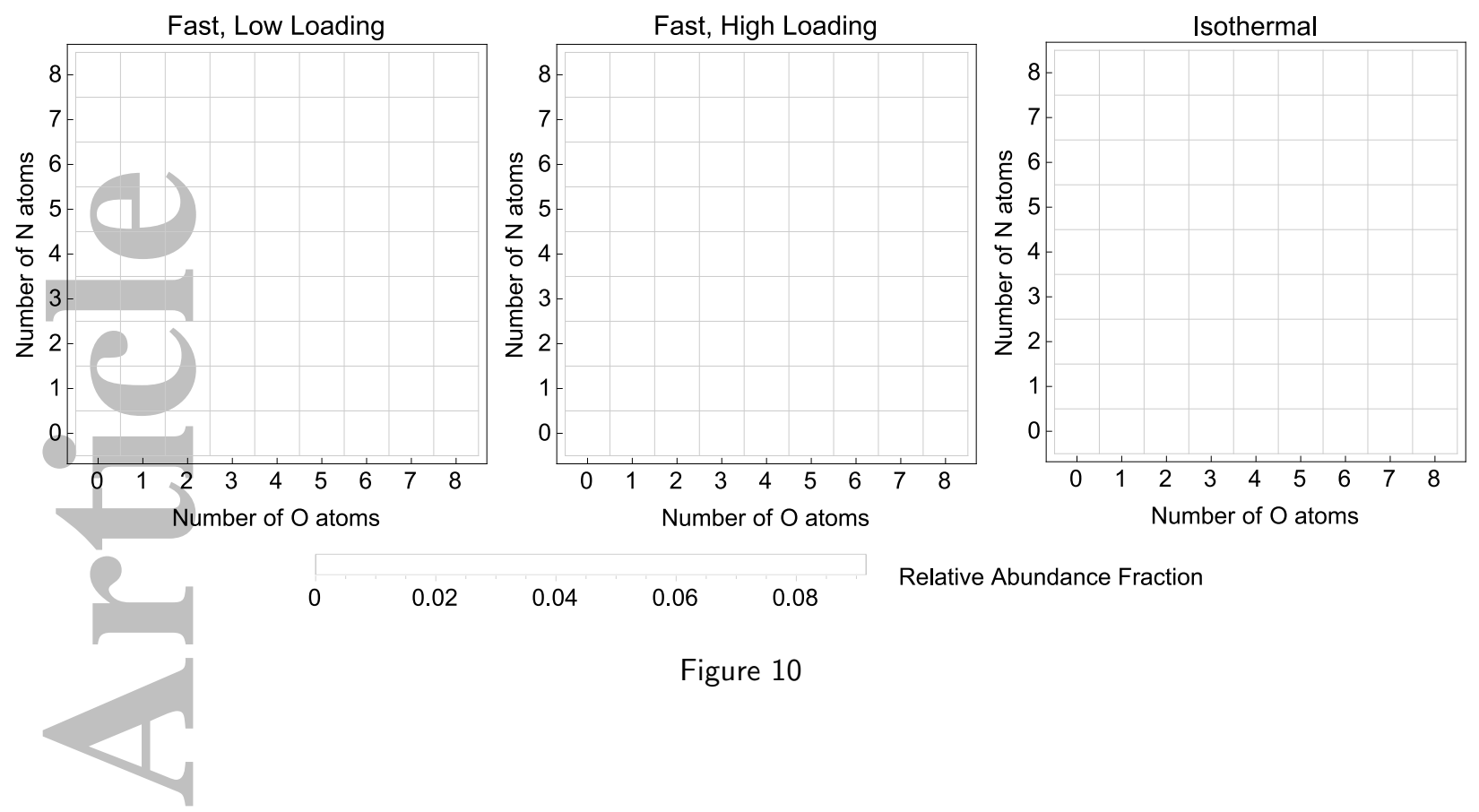

Figure 10

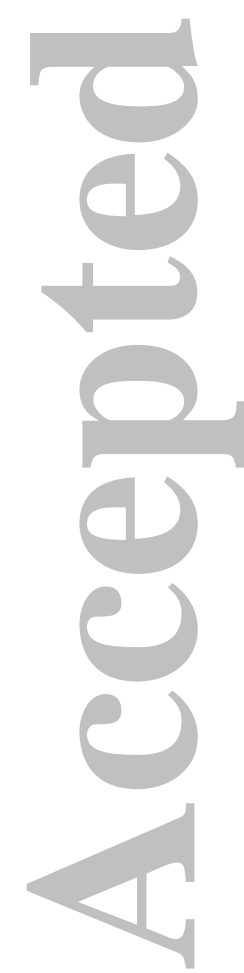




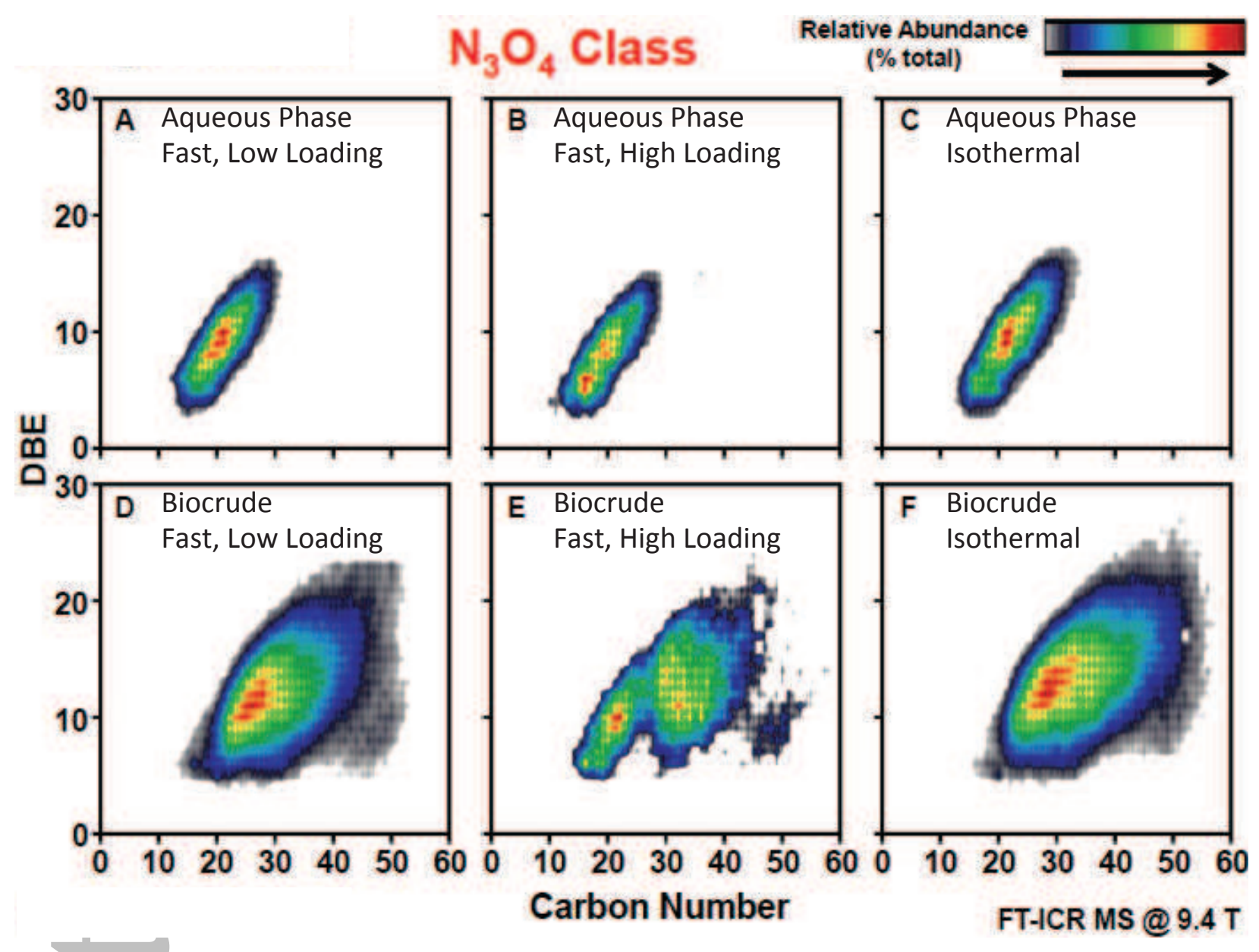

Figure 11 

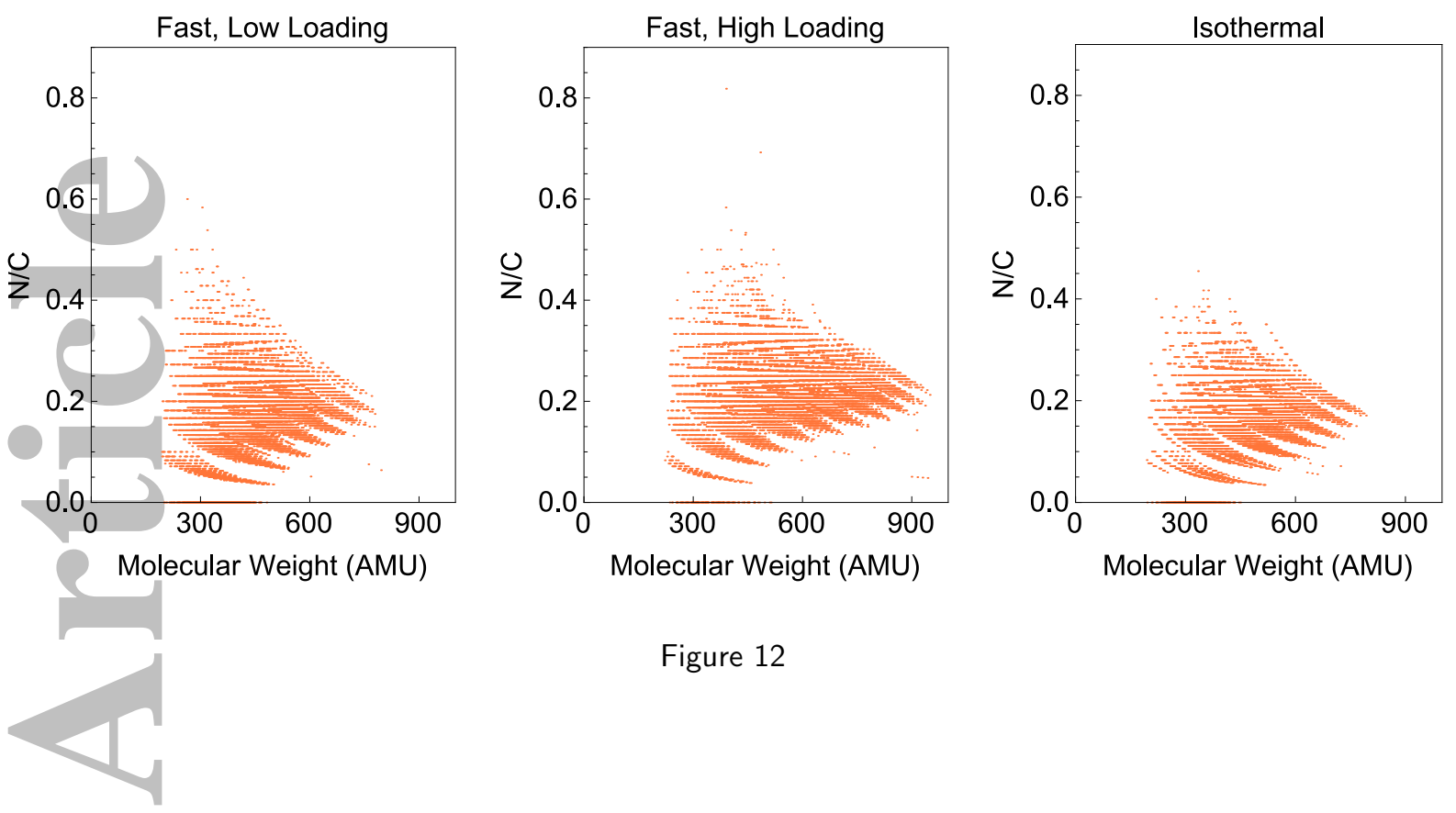

Figure 12

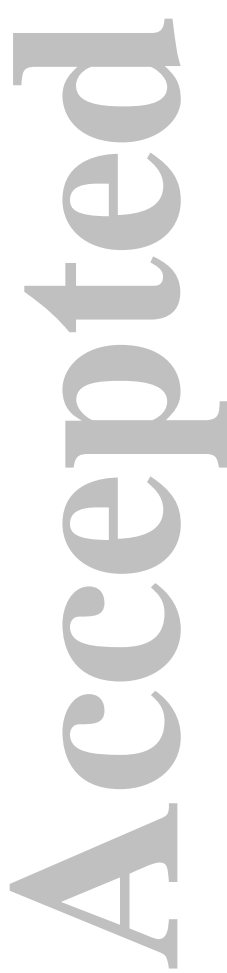



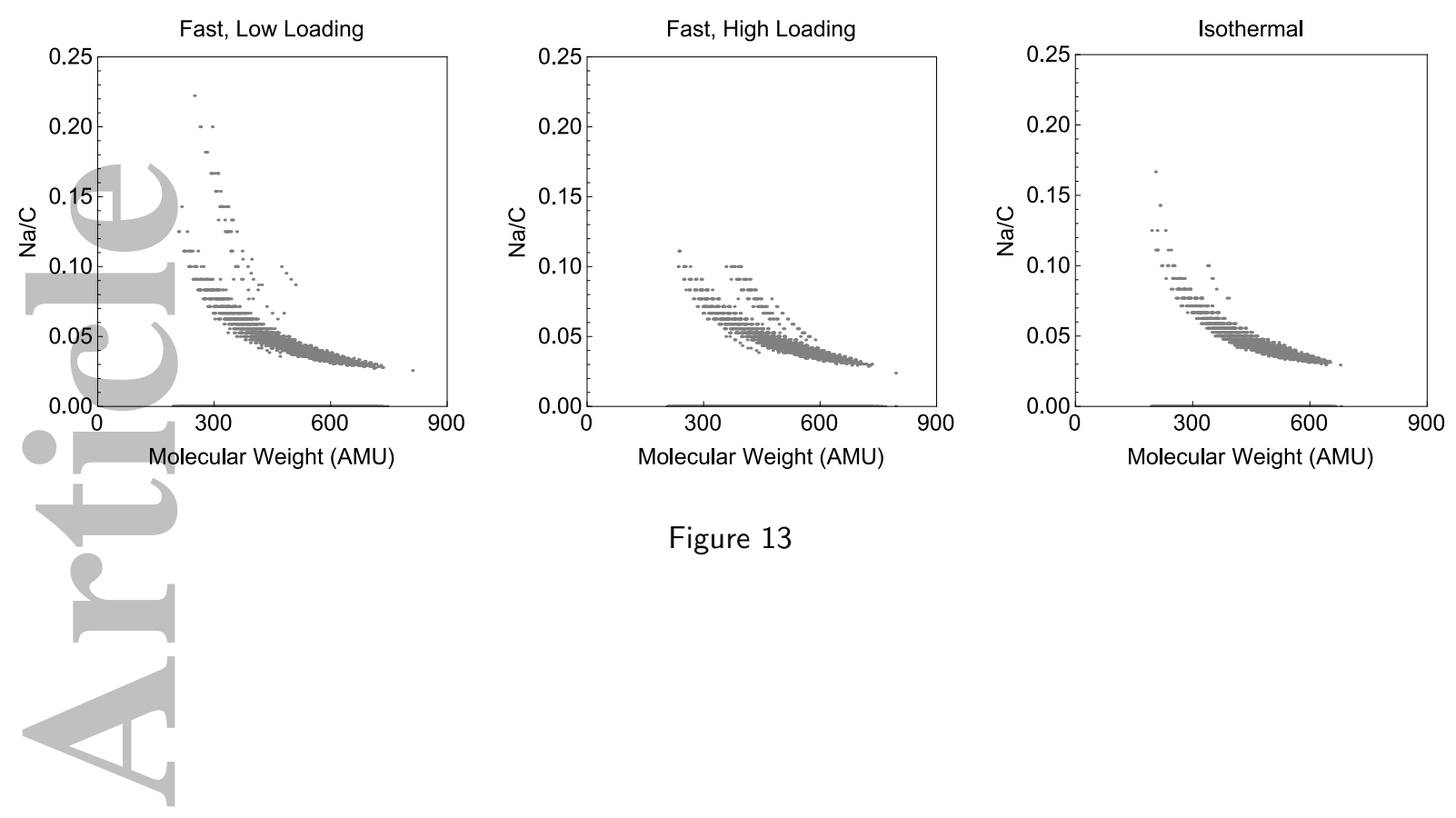

Figure 13

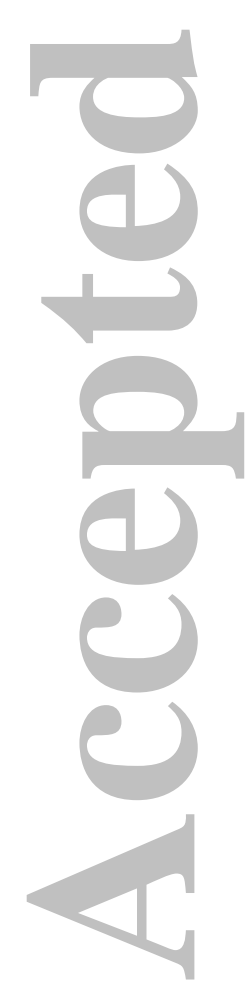



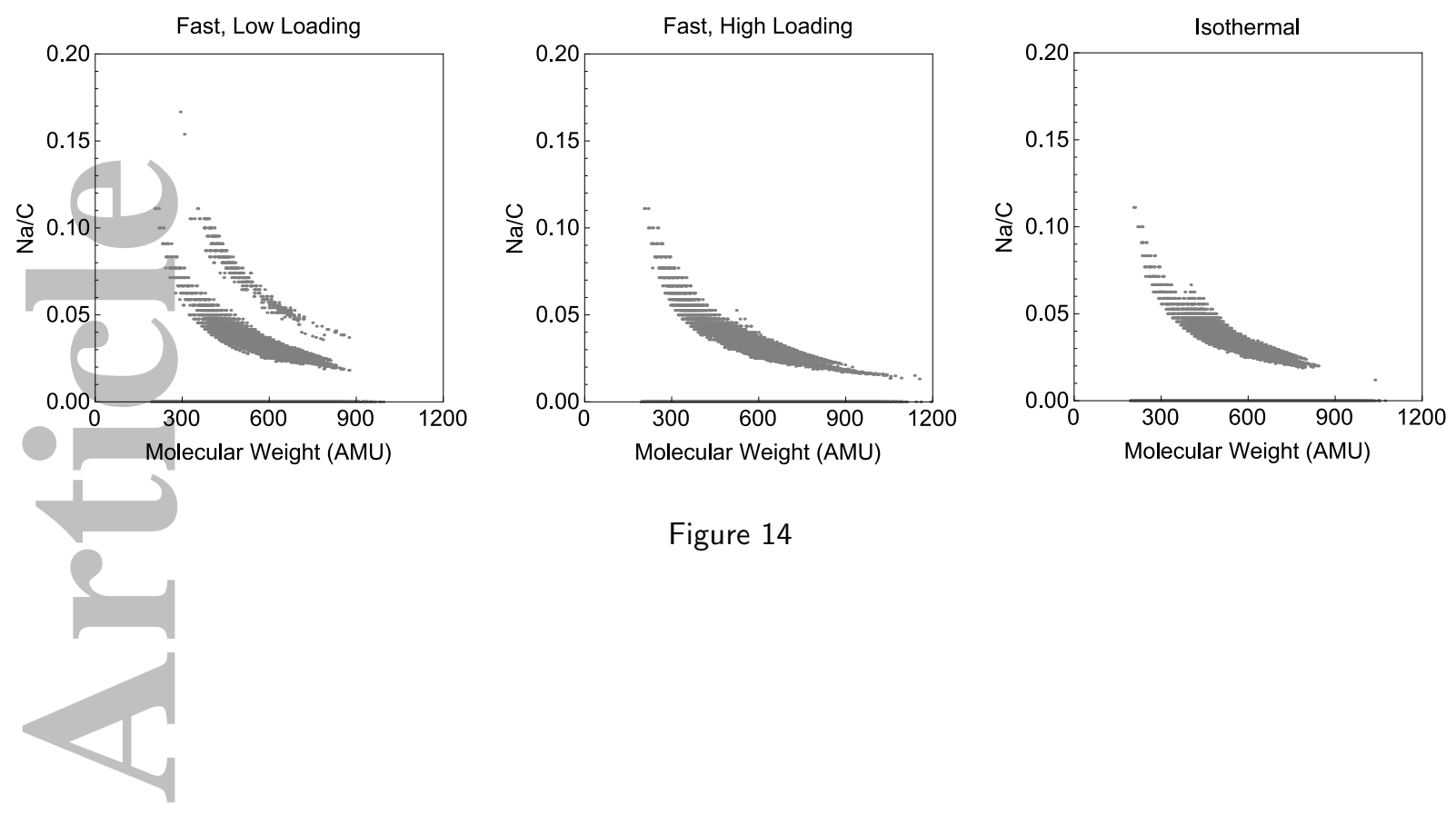

Figure 14

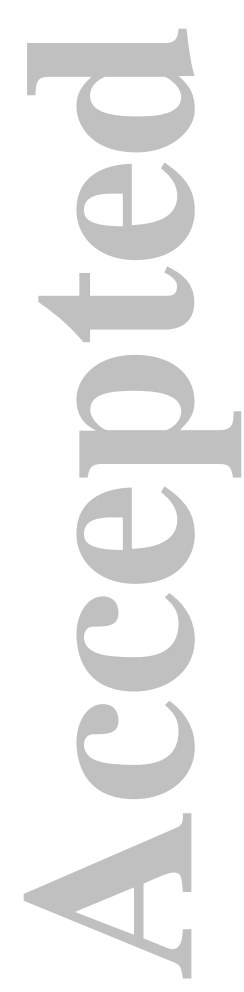



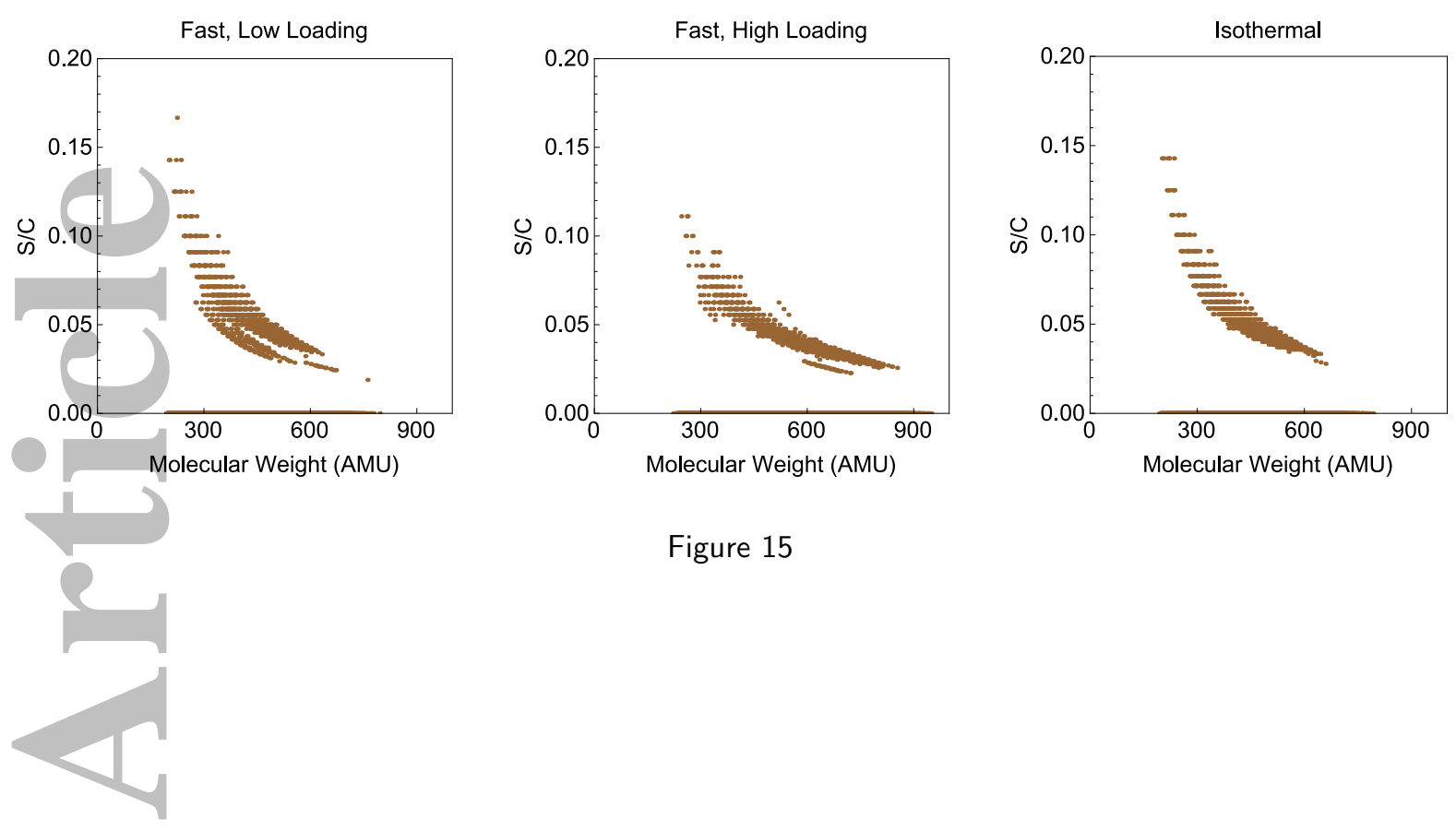

Figure 15

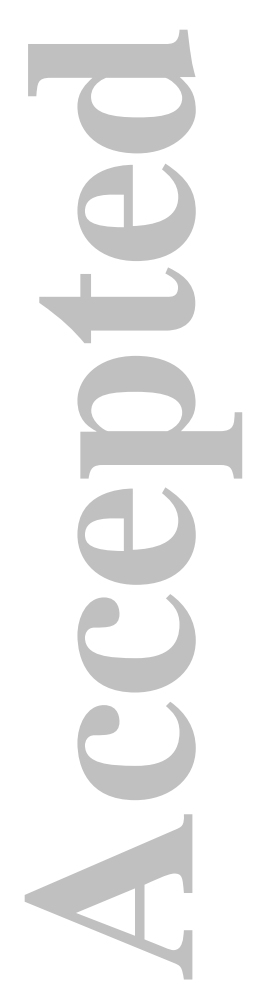

41

AlChE Journal

This article is protected by copyright. All rights reserved. 


\section{List of Tables}

Tab. 1: Reaction Conditions for Fast and Isothermal HTL

Tab. 2: HTL Product Yields on a (wt \%) Dry Weight Basis

Tab. 3: Yield (mmol/g dry algae) of Gaseous Products from HTL

Tab. 4: Elemental Composition (wt \%) of Dried Aqueous Phase Samples from HTL

Tab. 5: Elemental Composition (wt \%) of Biocrude Samples from HTL
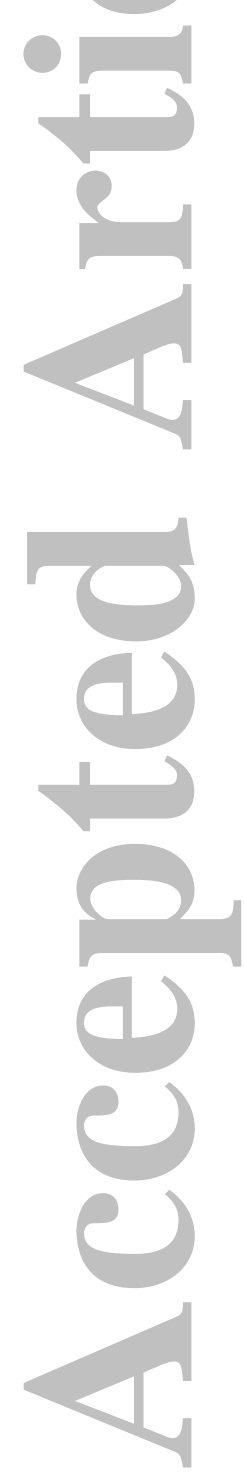


\section{List of Figures}

Fig. 1: Temperature Profiles for Fast and Isothermal HTL

Fig. 2: Reactions Likely to Occur During HTL

Fig. 3: Positive ESI FT-ICR MS Broadband Spectra of Aqueous Phase Samples from HTL (A - Fast HTL with Low Loading, B - Fast HTL with High Loading, C - Isothermal HTL)

Fig. 4: Venn Diagrams Illustrating Relative Numbers of Unique Molecular Formulae Identified in HTL Products by FT-ICR MS (Left = Positive ESI, Overlap = Both, Right = Negative ESI)

Fig. 5: Carbon Number Distributions for Negative ESI Analysis of Biocrude Samples

Fig. 6: Carbon Number Distributions for Negative ESI Analysis of Aqueous Phase Samples

Fig. 7: van Krevelen Plot (H/C and O/C Ratios) for Negative ESI Analysis of Aqueous Phase Samples

Fig. 8: van Krevelen Plots ( $\mathrm{H} / \mathrm{C}$ and O/C Ratios) for Positive ESI Analysis of Biocrude Samples

Fig. 9: Heteroatom Density Graph for Aqueous Phase Samples (Negative ESI)

Fig. 10: Heteroatom Density Graph for Biocrude Samples (Positive ESI)

Fig. 11: Isoabundance Contour Plots for Aqueous Phase and Biocrude Samples (Positive ESI)

Fig. 12: N/C Ratios vs. Average Molecular Weight for Negative ESI Analysis of Aqueous Phase Samples

Fig. 13: $\mathrm{Na} / \mathrm{C}$ Ratios vs. Average Molecular Weight for Aqueous Phase Samples (Positive ESI)

Fig. 14: Na/C Ratios vs. Average Molecular Weight for Biocrude Samples (Positive ESI)

Fig. 15: S/C Ratios vs. Average Molecular Weight for Aqueous Phase Samples (Negative ESI)

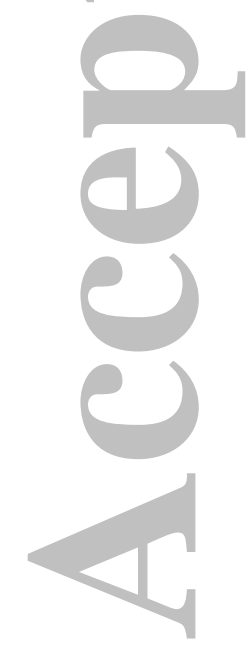

